\title{
Juses
}

\section{CRUISE REPORT FOR 01-99-SC SOUTHERN CALIFORNIA EARTHQUAKE HAZARDS PROJECT}

By William R. Normark, Jane A. Reid, Ray W. Sliter, David Holton, Christina E. Gutmacher, Michael A. Fisher, and Jonathan R. Childs

Open-File Report \# OF 99-560

1999

This report is preliminary and has not been reviewed for conformity with U.S. Geological Survey editorial standards or with the North American Stratigraphic Code. Any use of trade, product, or firm names is for descriptive purposes only and does not imply endorsement by the U.S. Government

\section{U.S. DEPARTMENT OF THE INTERIOR}

\section{U.S. GEOLOGICAL SURVEY}

Menlo Park, California 


\section{INTRODUCTION}

\section{Project objectives}

The focus of the Southern California Earthquake Hazards project is to identify the landslide and earthquake hazards and related ground-deformation processes occurring in the offshore areas that have significant potential to impact the inhabitants of the Southern California coastal region. The project activity is supported through the Coastal and Marine Geology Program of the Geologic Division of the U. S. Geological Survey (USGS) and is a component of the Geologic Division's Science Strategy under Goal 1 --- Conduct Geologic Hazard Assessments for Mitigation Planning (Bohlen et al., 1998). The project research is specifically stated under Activity 1.1.2 of the Science Strategy: Earthquake Hazard Assessments and Loss Reduction Products in Urban Regions. This activity involves “......research, seismic and geodetic monitoring, field studies, geologic mapping, and analyses needed to provide seismic hazard assessments of major urban centers in earthquake-prone regions including adjoining coastal and offshore areas." The southern California urban areas, which form the most populated urban corridor along the U.S. Pacific margin, are among a few specifically designated for special emphasis under the Division's science strategy (Bohlen et al., 1998).

The primary objective of the project is to help mitigate the earthquake hazards for the Southern California region by improving our understanding of how deformation is distributed (spatially and temporally) in the offshore with respect to the onshore region. To meet this objective, we are conducting field investigations to observe the distribution, character, and relative intensity of active (i.e., primarily Holocene) deformation within the basins and along the shelf adjacent to the most highly populated areas (Fig. 1). In addition, acoustic imaging should help determine the subsurface dimensions of the faults and identify the size and frequency of submarine landslides, both of which are necessary for evaluating the potential for generating 
destructive tsunamis in the southern California offshore. In order to evaluate the strain associated with the offshore structures, the initial results from the field mapping under this project will be used to identify possible sites for deployment of acoustic geodetic instruments to monitor strain in the offshore region. A major goal of mapping under this project is to provide detailed geologic and geophysical information in GIS data bases that build on the earlier studies and use the new data to precisely locate active faults and to map recent submarine landslide deposits.

\section{Study area}

The priorities for the field-mapping program under this hazards project are keyed to those areas with the greatest potential for impact on the Southern California populace: 1) the coastal strip (coastal zone and continental shelf) between Los Angeles and San Diego, where much of the hazard appears to be associated with strike-slip or obliqueslip faults; 2) active faults within the Santa Monica, San Pedro, and San Diego Trough basins, where more extensive sedimentation has left a greater stratigraphic record; 3) the offshore extension into the Santa Barbara Basin of the fold and thrust belt of the adjacent Western Transverse Range; 4) the boundary (Channel Islands region) between the inner California Borderland (strike-slip dominated deformation) and the Santa Barbara Channel (thrust and fold deformation). Figure 2 shows a generalized depiction of faults in the southern California region (adapted from Vedder et al., 1986 and Clarke et al., 1987). Further interpretation of the key structures of the inner California borderland are available from site-specific studies and regional tectonic syntheses (e.g., see Clarke et al., 1985; Ziony and Yerkes; 1985; Vedder et al., 1986; Vedder, 1987; Wallace, 1990; Legg, 1991; Crouch and Suppe; 1993, Klitgord and Brocher; 1996, Clarke and Kennedy, 1997; Dolan et al., 1997; Pinter et al., 1998; Bohannon and Geist, 1998; and Normark and Piper, 1998). 
Cruise 01-99-SC, the subject of this report, focused on the central and southeastern part of priority areas 1 and 2 noted above (Figs. 1, 3 and 4). The planned tracklines for the 01-99-SC survey were intended to both fill in gaps resulting from equipment problems during cruise A1-98-SC (Normark et al., 1999) and to extend the scope of the field work to the San Diego area (Fig. 3B). Tracklines were plotted at a 2$\mathrm{km}$ spacing aligned perpendicular to the shelf break and basin slope and on an conjugate set aligned to intercept major structural features that are oblique to the trend of the basin slope and shelf edge. The total trackline distance shown in the southeastern half of Figure 3B greatly exceeded the allowable survey time during $\mathrm{O} 1$ 99-SC. The distribution of survey time within areas 1 and 2 as noted above was intended to complete at least one of the conjugate set of the trackline grid at twokilometer spacings for areas that have multibeam bathymetric data. This was accomplished for the southeastern part of Santa Monica Bay and for the area southeast of Palos Verdes Peninsula (Fig. 4). A smaller area of the shelf and upper slope west of San Diego, where a high-resolution multibeam image is available, was also mapped in parts at a two-kilometer spacing. Between the San Pedro shelf and the San Diego area, the survey was conducted on a reconnaissance basis with fourkilometer spacing between planned survey lines using one grid orientation only (Fig. $4)$.

\section{OPERATIONS}

This section gives an overview of the vessel, equipment, personnel, and key operational events during the cruise. Many of the operational details of this cruise, as well as digital navigation and bathymetry files, are publically available with accompanying metadata through the USGS Western Region Coastal and Marine Geology (WRCMG) web site at:

http://walrus.wr.usgs.gov 


\section{Research platform}

The FY 1999 field program was conducted using a leased vessel, the 160-ft-long M/V OCEAN OLYMPIC, owned and operated by F/V North Wind, Inc. The M/V OCEAN OLYMPIC, which was initially designed as an offshore oilfield supply vessel, is currently outfitted as an Alaskan crab-fishing boat; prior to the cruise described herein, the vessel had not been used for geophysical surveying. There are no laboratory compartments on the M/V OCEAN OLYMPIC, but the large open fantail area is amenable to installation of standard container vans, each of which was outfitted for specific scientific function (Fig. 5). The M/V OCEAN OLYMPIC was staffed with a ship's crew of six, who provided diligent support to the project activity throughout the field operation.

For the cruise 01-99-SC, three of the four scientific vans installed on the M/V OCEAN OLYMPIC were the mainstay of the project survey activities: (1) an electronics lab/underway-watch van for operating the navigation system and primary geophysical instruments, (2) a mechanical shop used for maintaining the air compressor for the seismic-reflection sound source and the winches and davits used for launch and recovery of both the Huntec deep-towed boomer as well as the streamer and sound source for the high-resolution reflection profiling system; and (3) an office van that was also outfitted to provide a laboratory for sampling interstitial fluids from sediment cores. Figure $5 \mathrm{C}$ shows the layout of equipment on the vessel. The science vans and all associated deck equipment, including winches, davits, high-pressure air compressors, etc., were loaded during a three-day mobilization period at Redwood City, CA.

\section{Scientific Party}

The scientific party for 01-99-SC included four personnel from the southern California earthquake hazards project of WRCMG and four technical-support personnel from the WRCMG Marine Facilities staff (Table 1). In addition, there were 
four contract personnel, one to oversee operation of the deep-tow boomer and three to provide two-person daylight watch for marine mammals.

\section{General Operations}

The geophysical survey took place 6 to 17 June, 1999, with the ship departing from the port of Redwood City on 4 June 1999 (Table 2). During the 36-hour transit to the work area, final installation and testing of geophysical systems allowed the survey to begin on schedule. The general plan for survey lines during the cruise(Fig. 3B) and the final survey tracklines (Fig. 4) differ considerably. There was little loss of survey time as a result of equipment failure. Instead, the major impact on field operations was that the gas-injector (GI)-gun sound source for the multichannel seismic (MCS)-reflection system could only be used during daylight periods, when the contract marine-mammal observers were confidently able to determine whether whales came within $250 \mathrm{~m}$ of the vessel. Table 2 shows the milestones for the main operational activities and primarily shows those events that affected the collection of data; the table includes annotations for equipment failures and maintenance periods, changes between day and night operations, and interruptions in the collection of MCSreflection data as a result of encounters with marine mammals.

\section{Restrictions on use of the airgun sound source}

During the previous year's survey, which used the same seismic-reflection systems offshore of Los Angeles, the project contracted with Cascadia Research Collective to provide two personnel for continuous (24 hr/day) observation and recording of marine mammal sightings (Normark et al., 1999). In addition, the USGS voluntarily adhered to operational restrictions required by provisions of the Marine Mammal Protection Act. This meant that the multichannel sound sources (40 $\mathrm{in}^{3}$ air gun or $35 \mathrm{in}^{3} \mathrm{Gl}$ gun at different times during the cruise) would be shut down whenever marine mammals were observed within specified distances. The protocols for shut down of the sound sources were established prior to sailing, 
and the decision to shut down was vested solely with the marine-mammal observers and was not subject to veto by the chief scientist. Shutdown was required when baleen whales approached within $250 \mathrm{~m}$ of the sound source and when odontocetes (e.g., dolphins) or pinnipeds (e.g., seals) came within $100 \mathrm{~m}$. The protocol area was not a simple radius from the sound sources but an egg-shaped area that extended forward of and along the sides of the vessel by the stated protocol range. Sea lions, dolphins, and whales were observed numerous times during the survey, requiring shutdowns as frequently as several times a day. Most shutdowns were on the order of 2 to 8 minutes in length and tended to occur in the same general areas on each transit, e.g., dolphins feeding in waters above the upper slope, so it was not practical to retrace any trackline to acquire missing data. The report of the marine mammal observers for the 1998 operation is included as an appendix in Normark et al. (1999).

For the 1999 field operation, the National Marine Fisheries Service (NMFS), which is the agency empowered to enforce the Marine Mammal Protection Act (MMPA), required that the U.S. Geological Survey apply for an Incidental Harassment Authorization (IHA). The IHA request process takes nominally takes 120 days and the request was submitted to NMFS in mid-January 1999. One part of the IHA process requires NMFS to make the application available for public comment, which is done through notification in the Federal Register.

Following the publishing of the IHA request in the Federal Register, the California Coastal Commission (CCC) used authorization granted by provisions of the Coastal Zone Management Act to require the USGS to submit a Consistency Determination, which documents that a federal activity (in this case the geophysical survey) will be conducted in a manner consistent with the state's coastal-zone management program. The process of application to the CCC included discussion and review at a monthly meeting of the CCC, and for this cruise activity, the hearing was in May. The original request for a 'consistency 
determination' was denied as a result of action at the hearing, and the CCC requested that the USGS resubmit its request but with additional conditions, this time requesting a 'negative determination' (i.e. a finding that the proposed activity would have no effect on coastal-zone resources). The USGS complied and received verbal approval prior to the cruise. The most significant condition required by the CCC was that air-gun operations not be conducted during darkness.

After responding to questions from other parties (in addition to the CCC) raised as a result of the public comment period, there were followup discussions between the USGS and NMFS, and the USGS received the IHA on 3 June 1999. The IHA incorporated the conditions from the CCC and specified, among other restrictions, that:

(1) the USGS would have a minimum of three properly trained mammal observers approved in advance by NMFS to allow two observers on duty during daylight hours;

(2) the observers would record the effects of "seismic surveys and the resulting noise on marine mammals" and that monitoring would occur at all times the system was operating;

(3) the protocol for shut down of the sound source would be $100 \mathrm{~m}$ for dolphins, seals, and sea lions and $250 \mathrm{~m}$ for whales;

(4) the USGS would "not conduct seismic surveys with the Gl-gun sound source at night when visibility limits marine mammal detection within the designated safety zone"; and

(5) the results of the monitoring will be reported to NMFS within 120 days from the end of the geophysical survey (a draft report is required within 90 days). The daily operational scheme throughout the survey, therefore, was to conduct multichannel seismic work between about 0530 (just before sunrise) and 2015 (just after sunset) each day. The MCS gear was recovered while the vessel departed the survey line to conduct Huntec surveys in deep water where the tow vehicle would remain at a depth that exceeded the protocol range at the sea 
surface for dolphins and seals. Every morning, the vessel would have to rejoin the multichannel transects to pick up where MCS operation had left off the previous evening.

At the beginning of the field program, the marine-mammal observers provided a written protocol for the geophysical watchstanders with respect to meeting the conditions of the IHA. This marine-mammal protocol stated that: (1) the watchstander in the electronics lab will "contact .... mammal team to check if [the] area is clear of animals before" commencing use with the Gl gun (both in the morning during system startup and after any shutdown caused by mammal sightings or equipment problems; (2) the "mammal team" will contact the watchstanders in the electronic van "when light conditions are too poor to detect animals within the shutdown zone." All communication between the mammal team and the geophysical watchstanders was by radio using the same channel that was used for communication with the ship's bridge watch. Thus, all personnel on watch were aware of any communications affecting either the vessel or scientific operations regardless of which work area was initiating the transmission.

The written protocol also requested that the watchstanders were to shut down the Gl gun and immediately contact the mammal team "if animals are seen off the stern, clearly within [the] shut down area and haven't been detected by [the] mammal team."

All conditions stated in the protocol were followed throughout the cruise.

The program cost for meeting the requirements of the IHA are two fold. First, the number of pay periods of CMG personnel involved in the permitting process, which lasted from midDecember to early June, is equal to the number of pay periods for the 8-member CMG scientific staff during the transit and 12 days of survey. The salary cost for the staff involved in the permitting process is estimated at $\$ 32,000$. Second, loss of multichannel seismicreflection data collection during the night amounts to $38 \%$ of the total ship days contracted; 
for this year's 12-day survey, this amounts to more than $\$ 30,000$ of ship rental costs in lost survey time.

Another restriction on the survey resulted from the authority of the California State Lands Commission (SLC). The SLC has regulatory authority over waters within three miles of the coast. At the present time, the SLC bans all air-gun seismic sound sources regardless of size and regardless of the intended use, e.g., scientific research to define earthquake hazards cannot obtain an exemption to the ban. As a result, the survey with the Gl gun could not extend within three miles of the coast. The SLC does not have restrictions on non-airgun sources such as the Huntec boomer system, but the geophysical survey lines were terminated at the 3-mile limit because Huntec boomer data by itself is not sufficient for mapping the fault systems in this area.

Information on equipment shutdowns for both the Huntec and MCS equipment, caused either by mammal sightings, change of equipment, travel inside the 3 mile limit for the MCS, or port visits is given in Table 2. Except for the timing of the shutdowns, Table 2 does not log the activities of the marine-mammal observers from Cascadia Research Collective. Appendix 1 is the report provided by the Cascadia Research Collective detailing the recordings of the marine-mammal observers as required by the IHA.

\section{Equipment Review}

A brief description of and operational parameters for the primary survey equipment used during the cruise are given below. See also the web site referred to above. Shipboard positioning system

Position data was collected with the USGS-designed YoNav Navigation system, which can accept a wide range of input data including Global Positioning System (GPS), LORAN C (either hyperbolic or rho-rho), transit satellites, and microwave 
frequency, shore-based, transponder systems. The YoNav system is a PC-based data-acquisition and display program written in Microsoft $\mathrm{C} / \mathrm{C}++$ designed to provide navigation services on almost any DOS platform (Gann, 1992). The YoNav system incorporates line-generating tools, layers of geographical information (including trackline template and nautical chart data, e.g., major shipping lanes), and streaming GPS navigation data in order to display in real time the ship's position relative to the selected survey line. A YoNav dedicated PC was installed on the bridge for use by the captain and mates of the OCEAN OLYMPIC, who quickly adapted to the position display and were able to keep the ship within the defined line parameters for most of the survey. On this cruise, the YoNav system was configured to show one or more of several reference-data layers including bathymetric contours, shaded-relief images from multibeam-sounding data, tracklines of previous surveys, and compilations of seafloor structural features.

The YoNav system worked well, using GPS input to provide position data every six seconds for $24 \mathrm{hrs} /$ day. The preferred mode of operation was differential GPS, and there were minimal problems with the shore-based reference stations during the survey. Most of the periods without differential GPS were limited to a few minutes or tens of minutes. The logged intervals of degraded positional control generally indicate periods when there were sporadic position determinations that could be in error by as much as $10,000 \mathrm{~km}$, suggesting both bad data input and failure of YoNav to filter out bad data. Other positioning problems appeared to be internal to YoNav and are observable only at display scales around $10 \mathrm{~m} / \mathrm{cm}$.

The navigation file can be obtained at the web site noted earlier. 


\section{$\underline{\text { Huntec }}$}

A high-resolution Huntec Deep Tow System (DTS) boomer platform towed between $6 \mathrm{~m}$ and $160 \mathrm{~m}$ below the sea surface (depending upon the water depth) was used to image the upper few tens of milliseconds of strata with a resolution of better than $0.5 \mathrm{~ms}(<0.4 \mathrm{~m}$ at water velocity). Power output was 350 Joules, with a firing rate that was also dependent on water depth, ranging from $0.5 \mathrm{sec}$ over the shelf and upper basin slopes to $1.25 \mathrm{sec}$ over the deeper parts of the basins. The acoustic source spectra is from 0.5 to $8 \mathrm{kHz}$, peaking between 1.5 and $5 \mathrm{kHz}$. Returning signals were received primarily with a $7.6 \mathrm{~m}$ (25 ft) long Geoforce GF25/25P streamer, which is a 25-element hydrophone array that can be configured as a single channel, 25 element array or as a two-channel 15/10 element array. A backup 5-m-long Benthos 10-element array, which was the only receiver used in 1998, was also towed throughout the entire survey. Signals were filtered at $700-8000 \mathrm{~Hz}$ and recorded at a $0.25 \mathrm{sec}$ sweep. The data from the Geoforce array was recorded on paper using an EPC recorder; data from both hydrophone arrays were recorded on magneto-optical discs. The average survey speed of about $4 \mathrm{kt}(7.4 \mathrm{~km} / \mathrm{hr})$ resulted in a shot spacing between 1.5 and $2.5 \mathrm{~m}$ for the deep-tow boomer profiles.

The Huntec DTS operated throughout the cruise with the exception of three shutdowns: two for inspection of the towed hydrophone arrays and an unintended shutdown of the trigger pulse (Table 2). The Huntec was also off briefly during the sound-source-measurement experiment during the 17th of June (JD 168; Table 2).

During the early part of the cruise, when the survey was conducted in the area of the 1998 operation (Fig. 1 and Normark et al., 1999), the data quality provided by the Huntec system appeared comparable to the previous year's results. During the latter part of the 1999 cruise, however, the Huntec system was not providing similar quality data in deeper water areas (generally in water deeper than about $400 \mathrm{~m}$ ). In particular, the signal-to-noise ratio periodically made it difficult to track the sea floor in the deeper 
water areas (600 to $1100 \mathrm{~m}$ ). During partial disassembly of the tow vehicle during preparations to ship the system from San Diego, water was observed in a protective bladder on the back side of the boomer plates that might account for the degradation in record quality.

About $2300 \mathrm{~km}$ of Huntec survey data were obtained during the cruise.

\section{Multichannel seismic-reflection system}

The primary sound source for the multi-channel seismic-reflection profiling activity during the cruise was a 35/35 in ${ }^{3}$ double-chamber Gl gun firing every 12 seconds at a pressure of about 3000 psi. A Sureshot system was used to fire the gun in "harmonic mode" wherein the second chamber is delayed relative to the initial trigger pulse in order to achieve the cleanest signal by minimizing the bubble pulse. The most efficient settings for the Sureshot control are given in Normark et al. (1999). The GI gun was towed 12 meters behind the vessel and suspended from a float to maintain a depth of about 1 meter. There was only one failure of the Gl gun during the cruise resulting in a loss of about 2.5 hours of MCS data (Table 2). The failure appeared to result from wear on one or more of the O-ring seals in the gun.

The primary streamer for the MCS operation was a 24-channel ITI streamer with 10-m-long groups and 3 phones per group. Table 2 reviews the operational periods for the equipment.

Data were collected using a STRATAVIEW digital recording system and a Geometrics marine controller. Shots were triggered by the YoNav system. Data were recorded in SEGD format on 2-GB DAT tapes using a $1 \mathrm{msec}$ sample rate and a three second record length. A $60-\mathrm{Hz}$ notch filter was used; otherwise all frequency bands were passed. A total of approximately $1250 \mathrm{~km} 250$ hour of data were collected with the MCS system. Table 3 gives the start and end times for all multichannel survey lines. 


\section{Bathymetric profiling system}

A towed 12-kHz echo-sounding system was installed on the M/V OCEAN OLYMPIC to provide a continuous water-depth profile. The same davit and winch used for the 12 $\mathrm{kHz}$ towfish could be used to tow a $3.5 \mathrm{kHz}$ chirp-source system as a backup highresolution seismic-reflection system should the Huntec system fail. During transects across the basin slopes, when the water depth would change rapidly, the Huntec recording system requires frequent manual time-delay (scale) changes by the watchstander. An independent measure of the water depth is desirable to avoid using the Huntec to test seafloor physical properties. The ODEC (Ocean Data Equipment Corporation) recording system using the $12-\mathrm{kHz}$ transducer performed with no interruptions in data collection except a routine inspection of the tow vehicle (Table 2). An additional advantage in obtaining the $12-\mathrm{kHz}$ data was that the ODEC operating system utilizes a tracking gate to provide continuous depth information. The depth data were recorded in YoNav. Regular monitoring of the 12-kHz display monitor suggests that there were few problems with the digital depth data.

A summary of the locations of cruise information is given in Table 4.

\section{OVERVIEW OF SEISMIC-REFLECTION DATA}

This section briefly reviews the quality of the Huntec data and provides examples of how the data can be used to develop relative ages of stratigraphic sequences in the upper $50 \mathrm{~m}$ of slope/basin sediment. The selected examples illustrate (1) Huntec data on survey lines adjacent to profiles obtained in 1998 and 1999 (this cruise) and (2) the benefit of utilizing both Huntec and multichannel seismic-reflection profiles to interpret structural features. Figure 6 shows location of the profile segments selected for Figures $7,8,9$, and 10 . 
Both Huntec streamers (10 element and 25 element) were deployed continuously during the surveying this year, and the system operated with only two breaks to bring the tow vehicle to the sea surface to see whether the streamers were towing properly or were tangled. The data obtained will be used to evaluate the new Geoforce streamer with respect to the potential for improved data quality, e.g., signal to noise ratio. Figure $7 \mathrm{~A}$ and $\mathrm{B}$ compares data obtained this year from both streamers along a transect in relatively deep water that crosses the sloping toe of La Jolla fan where it merges with the nearly flat-lying sediment fill of San Diego Trough. In this case, the Geoforce streamer (Fig. 7A) clearly provides a better record of subbottom reflectors than the streamer used last year (Fig. 7B). Acoustic penetration is quite limited $(<20$ m), however, even with the new streamer.

During the last few days of surveying, which included the interval when the profiles of La Jolla fan (Fig. 7A and B) were obtained, the Huntec data quality was generally poor in mid- to deep-water areas (500 $\mathrm{m}$ to $1100 \mathrm{~m}$ depth). The problem of degraded record quality with increasing water depth had not been observed during the cruise in 1998 . Qualitative comparison of data between different cruises is subjective at best, especially when the data are not obtained over the same section of sea floor. Figure 7C shows a Huntec profile across the lower Dume fan in Santa Monica Basin that was obtained in 1998 using the same Benthos 10-element streamer that was used as a backup for this year. This example is selected because the water depth and sea floor morphology are very close to that of the La Jolla fan examples, and the profiles from both fans show a transition from a relatively steep, sandy submarine lower fan onto a basin floor underlain by essentially ponded turbidites (Piper, 1970; Piper et al., 1999). This comparison suggests that the Huntec system this year was not operating as effectively as it had in 1998 even with the newer streamer.

Figures 8A and 8B compare Huntec profiles obtained in 1998 and 1999 from the mid slope south of the Long Beach shelf (Fig. 6). The profile examples are parallel and 
separated by $2 \mathrm{~km}$ in Figure $8 \mathrm{~A}$; there is a course change at the east end of the segment of line 99L202 in Figure 8A such that the profiles almost converge near the eastern end of the line segments in Figure 8B. In these examples, the 1999 data appear to be quite comparable in quality and depth of acoustic penetration. Because the environmental conditions (e.g., sea state, wind, towing speeds, depth of tow) were the same both years, the favorable comparison of Figure 8 suggests that the record degradation observed later in the cruise (Fig. 7) might have resulted from a progressive decay in power output from the Huntec DTS boomer sound source during this year's survey.

Figure 8 also shows the effectiveness of the Huntec boomer data for evaluating late Quaternary sedimentation processes on the upper and mid slope. The numerous slope valleys show differing character of their most recent sediment fill. Only the western valley shown in line 99L202 and the eastern valley in line 66 (Fig. 8A) do not have a fill of transparent sediment; where it is observed, this fill varies in thickness among the valleys, e.g., the fill is thickest in the eastern valley on line 99L202 (Fig. 8A). Channel thalweg features are observed only in the valleys without acoustically transparent fill. If the thickness of acoustically transparent facies is a function of the length of time since active turbidity current deposition, then the relative ages of channel activity is determined. The shaded relief image of Figure 6B (Gardner and Mayer, 1998) is consistent with the Huntec interpretation in that the valley without acoustically transparent sediment fill has the most sharply defined morphology, which suggests youthfulness.

The western levee of the easternmost slope valley (Fig. 8B) shows a downslope transition in the acoustic facies of the levee sequences from more parallel bedded deposits upslope (line 99L202DL) compared to the short, discontinuous reflectors seen in line 66 (A1-98-SC). This difference in acoustic facies reflects the higher western levee on the upslope line; the higher levee receives more muddy sediment from the upper parts of the turbidity currents whereas farther downslope, the lower levee relief permits 
sandier accumulation. The east end of line 66 shows the muddier sediment of the continental slope dipping under the sandier turbidite channel deposits.

Fault disruption of the sediment fill in northern part of San Diego Trough was observed on many of the MCS lines. Locally, the MCS data record disruption deeper in the section but without clear effect on the uppermost part of the fill, e.g. Figure 9A. The accompanying Huntec record, however, shows that the disruption extends to the sea floor as well (Fig. 9B). There are several horizons of strong but discontinuous reflectors in the MCS data at about $1000 \mathrm{~m}$ depth that are suggestive of gas or hydrate accumulations (Fig. 9A).

In line 99L221 (Fig. 10), which is four kilometers south of the profile segment in Figure 9, there is evidence of a gas, or possibly gas hydrate, accumulation. About $45 \mathrm{~m}$ below the flat sea floor, an anomalous column of concave-upward reflections, which extend to about $200 \mathrm{~m}$ subbottom, is capped by a convex-upward reflection. The anomalous column of reflectors in San Diego Trough (Fig. 10) are within a zone about 800 m in width. Superficially, this column of reflectors gives the appearance of a VAMP (Velocity and AMPlitude) structure. VAMPs are "compound-velocity pseudostructures" with a velocity pullup over a pushdown that records "a localized body of massive gas hydrate of high acoustic velocity overlying a column of lowvelocity sediment containing free interstitial gas" (Scholl and Cooper, 1978; Scholl and Hart, 1993). Although common in the deep Bering Sea area (Scholl and Hart, 1993), VAMPs have not been widely observed elsewhere (D. W. Scholl, oral communication, 1999).

The reflection geometry of the acoustic anomaly in Figure 10 is probably not a VAMP because: (1) the relief (in two-way travel time) of the concave-upward reflections is too great to result from a low-velocity free-gas zone; and (2) the base of the methane gashydrate stability zone is at least 700 mbsf (Normark et al., in press). A alternate explanation for this acoustic anomaly is a buried mound of sediment containing gas hydrate and, possibly, authigenic carbonate. The convex-upward reflection is the upper surface of this buried mound, which formed by gas/fluid migration above the diapiric 
structure underlying the acoustic anomaly (Figure 10). Possible bottom-simulating reflectors (BSRs) and bright spots have been observed elsewhere in the MCS surveys for this study, but the acoustic anomaly recorded in line 99L221 is the clearest evidence for a gas or gas hydrate accumulation in the basins offshore southern California.

\section{DISCUSSION AND SUMMARY}

As shown in the examples discussed above, the MCS and Huntec seismic-reflection systems deployed for the 1999 earthquake-hazard survey generally provided satisfactory information for defining structures in the upper kilometer of the inner-basin areas. Recognition of active faults is enhanced where high-resolution multibeam bathymetric data are also available (Bohannon et al., 1998; Marlow et al., 1999). For this reason, as well as recognizing the greater potential for earthquake-related societal disruption in these more heavily populated segments of coastal California, the survey priorities were adjusted to obtain more closely spaced survey lines from the areas off Santa Monica, San Pedro, and San Diego. During the survey time available with the M/V OCEAN OLYMPIC, $1250 \mathrm{~km}$ of MCS and concurrent Huntec profiles were obtained. An additional $1050 \mathrm{~km}$ of Huntec high-resolution profiles will help map a few faults in those areas where sufficient MCS and single-channel seismic-reflection data already exist to permit interpretation of the earthquake hazards. The inability to collect MCS data during the night hours, however, results in a paucity of data for some apparently active structural features, which thus reduces the confidence of our interpretation for these structures on the inner basin margins and continental shelf. Additional survey time will be required (especially within the 3-mile limit) to complete mapping the offshore earthquake hazards in the coastal zone. 


\section{ACKNOWLEDGMENTS}

We thank the captain and crew of the M/V OCEAN OLYMPIC for their enthusiasm and support of the field program. Kevin O'Toole, Larry Kooker, Hal Williams, and Fred Payne from the WRCMG Marine Facilities support group led the conversion efforts to refit the fishing vessel M/V OCEAN OLYMPIC as a geophysical survey vessel; they were ably assisted by Graham Standon of Geoforce, who was responsible for operation of the Huntec DTS. We also thank Jen Quan and John Calambokidis for timely report on marine mammal observations during the cruise. Michael Marlow provided a critical review of the report.

\section{REFERENCES CITED}

Bohannon, R. G. and Geist, E., 1998, Upper crustal structure and Neogene tectonic development of the California continental borderland: Geol. Soc. Amer. Bull., v. 110, p. $779-800$.

Bohannon, R. G., Gardner, J. V., Sliter, R., and Normark, W. R., 1998, Seismic hazard potential of offshore Los Angeles Basin based on high-resolution, multibeam bathymetry and close-spaced, seismic-reflection profiles: EOS, Transactions Amer. Geophys. Union, v. 79, p. F818.

Bohlen, S. R., Halley, R. B., Hickman, S. H., Johnson, S. Y., Lowenstern, J. B., Muhs, D. R., Plumlee, G. S., Thompson, G. A., Trauger, D. L., and Zoback, M. L., 1998, Geology for a changing world: A science strategy for the Geologic Division of the U.S. Geological Survey, 2000-2010: U.S. Geological Survey Circular 1172, 59p. Clarke, S. H., and Kennedy, M. P., 1997, Analysis of late Quaternary faulting in the Los Angeles Harbor area and hazard to the Vincent Thomas Bridge: California Dept. of Conservation, Division of Mines and Geology Open-File Report 97-10, $50 p$, 10 figures, 5 plates. 
Clarke, S. H., Greene, H. G., and Kennedy, M. P., 1985, Identifying potentially active faults and unstable slopes offshore: In Ziony, J. I. (Ed), Evaluating earthquake hazards in the Los Angeles region: an earth-science perspective: U.S. Geological Survey Professional Paper 1360, p. 347-496.

Clarke, S. H., Greene, H. G., Kennedy, M. P. and Vedder, J. G., 1987, Geologic map of the inner--southern California continental margin --- Map 1A (Geology), Area 1 of 7, In Greene, H. G. and Kennedy, M. P., eds, 1987, California continental margin geologic map series: Sacramento, CA (California Division of Mines and Geology), scale 1:250,000.

Crouch, J. K. and Suppe, J., 1993, Late Cenozoic tectonic evolution of the Los Angeles Basin and inner California Borderland: a model for core complex-like crustal extension: Geol. Soc. Amer. Bull., v. 105, 1415-1434.

Dartnell, P. and Gardner, J. V., 1999, Sea-floor images and data from multibeam surveys in San Francisco Bay, southern California, Hawaii, the Gulf of Mexico, and Lake Tahoe, California-Nevada: U. S. Geological Survey Digital Data Series DDS-55, version 1.0 .

Dolan, J. F., Sieh, K., Rockwell, T. K., Guptill, P., and Miller, G., 1997, Active tectonics, paleoseismology, and seismic hazards of the Hollywood fault, northern Los Angeles basin, California: Geol. Soc. Amer. Bull., v. 109, p. 1595-1616.

Gann, J. T., 1992, YoNav: Your own integrated navigation system for DOS platforms, U.S. Geological Survey Open-File Report 92-565, 62p.

Gardner, J. V., and Mayer, L. A., 1998, Cruise Report RV Ocean Alert Cruise A2-98SC, Mapping the southern California continental margin. US Geological Survey Open-File Report. 98-475, 26p.

Klitgord, K.D., and Brocher, T., 1996, Oblique-slip deformation in the San Pedro Basin offshore Southern California: EOS, Trans. Amer. Geophys. Union, v. 77, p. F737. 
Legg, M. R., 1991, Developments in understanding the tectonic evolution of the California Continental Borderland: SEPM Society for Sedimentary Geology Special Publication 46, p. 291-312.

Marlow, M. S., Bohannon, R. G., Gardner, J. V., Normark, W. R. and Simpson, R. W. Jr., 1999, Palos Verdes Fault Complex: An Example of Fault Segmentation in Offshore Southern California: Geological Society of America, Abstracts with Programs, v. 31, p. A-128.

Normark, W. R., and Piper, D. J. W., 1998, Preliminary evaluation of recent movement on structures within the Santa Monica Basin, offshore southern California: U. S. Geological Survey Open File Report 98-518, 60 p.

Normark, W. R., Bohannon, R. G., Sliter, R., Dunhill, G., Scholl, D. W., Laursen, J., Reid, J. A., and Holton, D., 1999, Cruise report for A1-98-SC Southern California earthquake hazards project: U.S. Geological Survey Open-File Report No. 99$152,60 \mathrm{p}$.

Normark, W.R., Sliter, R., Hart, P.E., and Holton, D.J., (in press), Evidence for a Buried Gas-Hydrate Mound in Turbidite Fill of the Gulf of Santa Catalina, Offshore Southern California: EOS, Trans. Amer. Geophys. Union.

Pinter, N., Lueddecke, S. B., Keller, E. A., and Simmons, K. R., 1998, Late Quaternary slip on the Santa Cruz Island fault, California: Geol. Soc. Amer. Bull., v. 110, p. 711-722.

Piper, D.J.W., 1970, Transport and deposition of Holocene sediment on La Jolla deepsea fan, California: Marine Geology, v. 8, p. 211-227.

Piper, D.J.W., R.N. Hiscott, and W.R. Normark, 1999, Outcrop-scale acoustic facies analysis and latest Quaternary development of Hueneme and Dume submarine fans, offshore California: Sedimentology, v. 46, p. 47-78. 
Scholl, D. W., and Cooper, A. K., 1978, VAMPs --- possible hydrocarbon-bearing structures in Bering Sea Basin: Amer. Assoc. of Petroleum Geologists Bull., v. 62, p. 2481-2488.

Scholl, D. W., and Hart, P. E., 1993, Velocity and amplitude structures on seismicreflection profiles --- possible massive gas-hydrate deposits and underlying gas accumulations in the Bering Sea Basin: U.S. Geological Survey Professional Paper 1570, p. 331-351.

Vedder, J. G., 1987, Regional geology and petroleum potential of the Southern California Borderland, In Scholl, D. W., Grantz, A., and Vedder, J. G., eds., Geology and Resource Potential of the Continental Margin of Western North America and Adjacent Ocean Basins --- Beaufort Sea to Baja California, CircumPacific Council for Energy and Mineral Resources Earth Science Series, v. 6 (Houston, TX), p. 403-447.

Vedder, J.G., Greene, H.G., Clarke, S.H., and Kennedy, M.P., 1986, Geologic map of the mid-southern California continental margin --- Map 2A (Geology), Area 2 of 7, In Greene, H. G. and Kennedy, M. P., eds, 1986, California continental margin geologic map series: Sacramento, CA (California Division of Mines and Geology), scale 1:250,000.

Wallace, R. E., ed., 1990, The San Andreas Fault System, California: U.S. Geological Survey Professional Paper 1515, 283 pp.

Ziony, J. I., and Yerkes, R. F., 1985, Evaluating earthquake and surface-faulting potential: In Ziony, J. I. (Ed), Evaluating earthquake hazards in the Los Angeles region: an earth-science perspective: U.S. Geological Survey Professional Paper 1360, p. 43-91. 


\section{FIGURE CAPTIONS}

FIGURE 1: Physiography of the southern California borderland showing the major basins and islands. The study area for the offshore earthquake hazards project includes the innermost basins and islands and extends from the western margin of Santa Barbara Basin to the Mexican-U.S. EEZ boundary southwest of San Diego. The areas of the 1998 and 1999 survey are shown. Dashed green line shows area in which gaps in surveying during 1998 were filled during 1999.

FIGURE 2: Generalized fault and fold map for the inner southern California borderland compiled from Vedder et al. (1986) and Clarke et al. (1987).

FIGURE 3: (A) Trackline map showing multichannel seismic-reflection (MCS) data obtained during previous field data acquisition under this project. (B) Precruise plan of survey tracklines for this year's cruise (O1-99-SC). The survey priorities included filling parts of the 1998 survey grid in areas where the multichannel system was unavailable during the 1998 survey (Fig. 1; Normark et al, 1999). Optimal grid spacing is two kilometers on both sets of tracklines.

FIGURE 4: Trackline plot for O1-99-SC survey showing only the MCS survey lines. MCS data obtained during previous field-data acquisition (1997 and 1998) is shown with dashed gray lines (see Fig. 3A).

FIGURE 5: Photos of the M/V OCEAN OLYMPIC showing placement of the laboratory vans and other deck equipment. (A) M/V OCEAN OLYMPIC; (B) deploying GI gun in predawn twilight to be ready to commence MCS data collection when visibility is sufficient for the marine mammal observers; (C) deck vans (view aft) with office van in foreground, mechanical shop 
behind to left, electronics van behind to right, and the core van (farthest aft).

FIGURE 6: (A) Location of profiles shown in Figures 7 to 10; box encompassing the profiles of Figure 8 shows the area depicted in the inset (B) with shadedrelief image (adapted from Dartnell and Gardner, 1999) showing the complexity in the submarine channel pattern where lines 99202 and (98)66 cross on the basin slope. Long dashes and short dashes for tracklines in $\mathrm{B}$ depict profile segments in Figures $8 \mathrm{~A}$ and $8 \mathrm{~B}$ respectively; line 99L202-99L202DL is the uppermost trackline with the course change required to remain outside the three-mile limit.

FIGURE 7: Huntec deep-tow boomer profiles from the lower reaches of two sandy fans, La Jolla fan in San Diego Trough and Dume fan in Santa Monica Basin, that lie in similar water depths to show the difference between data obtained in 1998 and 1999. (A and B) Line 99N940 from cruise O1-99-SC. Profile A was recorded using the Geoforce 25-channel array and profile B with the Benthos 10-element array that was also used for the 1998 survey. (C) Line 28 from cruise A1-98-SC using the Benthos array. Profile locations in Figure 6.

FIGURE 8: Huntec deep-tow boomer profiles from adjacent survey lines across the upper basin slope south of Long Beach showing the relative quality of data obtained in 1998 and 1999. (A) lines 99L202 (1999) and 66 (1998); (B) Lines 99L202DL (1999) and 66 (1998) that are the eastward continuation of the profile segments in $8 \mathrm{~A}$. The profiles have been approximately aligned by longitude. Profile locations in Figure 6 . Bold $L$ denotes channel levee. 
FIGURE 9: (A) Multi-channel seismic-reflection data from lines 99L219 south of Dana Point, California. (B) Huntec profile along the same interval shown in the MCS data. This MCS segment of line 219 shows a major discontinuity in the sediment fill of the basin deeper than about 200 ms sub-seafloor. Bright reflectors suggest that gas might be accumulating locally. The Huntec data across this area shows about 3 to $4 \mathrm{~m}$ of offset of the sea floor and reflectors in the upper $15 \mathrm{~m}$ of sediment. The Huntec record is of poor quality below $20 \mathrm{~m}$ subbottom but does suggest there has been gentle folding of the strata as seen in the MCS profile. Profile locations in Figure 6.

FIGURE 10: Segment of MCS data from line 99L221 that shows an anomalous acoustic pattern with a column of concave-upward reflections capped by a convex-upward reflection in the basin sediment fill, in which the reflectors are otherwise flat-lying or with gentle dips. The top of this column occurs at a horizon $~ 45 \mathrm{~m}$ below the sea floor and probably results from a gas hydrate mound. Profile location in Figure 6. 
Table 1. Scientific Personnel

\begin{tabular}{||l|l|l}
\hline \multicolumn{1}{|c|}{$\begin{array}{c}\text { Crew Person } \\
\text { (First Last) }\end{array}$} & \multicolumn{1}{c|}{$\begin{array}{c}\text { Crew Organization } \\
\text { (i.e., USGS) }\end{array}$} & \multicolumn{1}{c}{ Crew Responsibilities } \\
\hline \hline Bill Normark & USGS & Chief Scientist \\
\hline Jane Reid & USGS & Watchstanding: YoNav and Huntec \\
\hline Ray Sliter & USGS & Watchstanding: multichannel seismic \\
\hline Dave Holton & Environmental Careers Org. & Watchstanding: YoNav and Huntec \\
\hline Larry Kooker & USGS & Electronics Technician \\
\hline Fred Payne & USGS & Electronics Technician \\
\hline Kevin O'Toole & USGS & Mechanical Technician \\
\hline Hal Williams & USGS & Mechanical Technician \\
\hline Graham Standen & Geoforce Consultants & Huntec specialist \\
\hline Jen Quan & Cascadia Research Collective & Marine mammal observer \\
\hline Annie Douglas & Cascadia Research Collective & Marine mammal observer \\
\hline Tamara Guenther & Cascadia Research Collective & Marine mammal observer \\
\hline Russ Brisendine & F/V North Wind, Inc. & Ship Captain \\
\hline Jeff Stringer & F/V North Wind, Inc. & $1^{\text {st } \text { Mate }}$ \\
\hline Dave Malsch & F/V North Wind, Inc. & Engineer \\
\hline Michael Hill & F/V North Wind, Inc. & Cook \\
\hline Paul Giron & F/V North Wind, Inc. & $2^{\text {nd }}$ Mate \\
\hline Joe Kelly & F/V North Wind, Inc. & A/B \\
\hline \hline
\end{tabular}


Table 2. Operational Log

Local time is 7 hours behind Julian Day (JD) and Greenwich Mean Time (GMT)

\begin{tabular}{|c|c|}
\hline $\begin{array}{l}\text { DATE/TIME } \\
\text { JD/GMT }\end{array}$ & ACTIVITY \\
\hline $155 / 1520$ & Departed USGS Marine Facilities, Port of Redwood City \\
\hline$\overline{156 / 1705}$ & $\begin{array}{l}\text { Slow to test new } 12-\mathrm{kHz} \text { transducer (in towed housing) compatibility } \\
\text { with old model deck unit; also test } 3.5-\mathrm{kHz} \text { system with same deck } \\
\text { unit and test/tune deep-tow Huntec vehicle using both old and new } \\
\text { streamers }\end{array}$ \\
\hline $156 / 2210$ & Resume full speed to operations area \\
\hline $157 / 0326$ & Arrive in operations area and slow to deploy gear \\
\hline $157 / 0402$ & $\begin{array}{l}\text { Begin operations in night time configuration, i.e., 12-kHz echo } \\
\text { sounding and Huntec boomer systems only }\end{array}$ \\
\hline $157 / 0820$ & Brief Huntec power interruption; little data lost \\
\hline $157 / 1310-1327$ & $\begin{array}{l}\text { Slow to deploy multichannel streamer and Gl gun for 'daylight' } \\
\text { operations }\end{array}$ \\
\hline$\overline{157 / 1327}$ & $\begin{array}{l}\text { Begin daylight operations with multichannel seismic-reflection } \\
\text { system (MCS); } 12-\mathrm{kHz} \text { echo sounder and Huntec boomer systems } \\
\text { remain operational during launch and recovery of MCS components }\end{array}$ \\
\hline $157 / 2017-2020$ & Shutdown called by "mammal team" -i.e., Gl gun trigger off \\
\hline $157 / 2353-2355$ & Shutdown called by "mammal team" \\
\hline $158 / 0332$ & $\begin{array}{l}\text { End daylight operation with MCS; vessel is slowed to retrieve both } \\
\text { the Gl gun and streamer before starting night time operations }\end{array}$ \\
\hline 158/1148-1207 & Slow to deploy MCS gear \\
\hline $158 / 1226$ & Start daylight operation with MCS \\
\hline 158/1334-1339 & Shutdown called by "mammal team" \\
\hline $158 / 1541-1542$ & Shutdown called by "mammal team" \\
\hline 158/1649-1655 & Shutdown called by "mammal team" \\
\hline 158/2032-2035 & Reconfigure tow depth for 12-kHz tow fish; system off \\
\hline 159/0043-0045 & Huntec system off; fish raised to inspect (reason not recorded) \\
\hline $159 / 0338$ & End daylight operation with MCS \\
\hline $159 / 0420-0426$ & $12-\mathrm{kHz}$ system off (reason not recorded) \\
\hline $159 / 1152$ & Slow to begin daylight operations with MCS \\
\hline $159 / 1230$ & Begin daylight operations with MCS \\
\hline 159/1752-1758 & MCS off; 'blue screen death' by recording system \\
\hline $159 / 2315-2319$ & Shutdown called by "mammal team" \\
\hline $160 / 0335$ & End daylight operation with MCS; slow to retrieve gear \\
\hline 160/1144-1209 & Slow to deploy gear for daylight operations with MCS \\
\hline $160 / 1233$ & Begin daylight operations with MCS \\
\hline 160/1537-1557 & 12-kHz system off; changing paper roll \\
\hline 160/2118-2120 & Shutdown called by "mammal team" \\
\hline $161 / 0317$ & End daylight operation with MCS \\
\hline $161 / 1146$ & Slow to begin daylight operations with MCS \\
\hline $161 / 1232$ & Begin daylight operations with MCS \\
\hline
\end{tabular}


Table 2, continued

\begin{tabular}{|c|c|}
\hline $161 / 1544$ & $\begin{array}{l}\text { USN vessel McCloskey establishes radio contact re: their generation } \\
\text { of 'acoustic noise'; USN agrees to hold off their activity until we are } \\
10 \text { n. miles away (moving on our current survey line). }\end{array}$ \\
\hline $162 / 0022-0024$ & Shutdown called by "mammal team" \\
\hline $162 / 0051$ & $\begin{array}{l}\text { End daylight operation with MCS because of GI gun failure. The } \\
\text { shutdown is approximately } 2.5 \text { hours before end of typical daylight } \\
\text { window. GI gun was repaired in about } 3 \text { hours, but mammal team did } \\
\text { not approve triggering a few test shots to see if repair measures were } \\
\text { adequate. }\end{array}$ \\
\hline 162/1155-1219 & $\begin{array}{l}\text { Slow to deploy and test Gl gun for air leaks; deploy streamer for } \\
\text { daylight operation with MCS }\end{array}$ \\
\hline $162 / 1246$ & Begin daylight operations with MCS \\
\hline $162 / 1304-1315$ & Huntec system trigger off --- cockpit error \\
\hline 162/1805-1847 & Gl gun shutdown at 3-mile limit \\
\hline $163 / 0336$ & End daylight operation with MCS \\
\hline 163/1147-1207 & Slow to deploy streamer and GI gun \\
\hline $163 / 1257$ & Begin daylight operations with MCS \\
\hline $163 / 1845-1907$ & $\begin{array}{l}12 \mathrm{kHz} \text { system off; tow fish hauled out for inspection (routine; no } \\
\text { problem being sought) }\end{array}$ \\
\hline $164 / 0322$ & End daylight operation with MCS \\
\hline $164 / 0330-0339$ & Slow to retrieve streamer and Gl gun \\
\hline 164/1144-1203 & Slow to deploy streamer and Gl gun \\
\hline $164 / 1225$ & Begin daylight operations with MCS \\
\hline $164 / 1523-1525$ & Shutdown called by "mammal team" \\
\hline $164 / 1533-1626$ & Gl gun shutdown at 3-mile limit \\
\hline $164 / 1623-1626$ & $\begin{array}{l}\text { Shutdown called by "mammal team" (coincident with 3-mile } \\
\text { limit shutdown) }\end{array}$ \\
\hline $165 / 0322$ & End daylight operation with MCS \\
\hline $165 / 1205-1225$ & Slow to deploy streamer and GI gun \\
\hline $165 / 1227$ & Begin daylight operations with MCS \\
\hline $165 / 1735-1739$ & Shutdown called by "mammal team" \\
\hline 165/1914-1916 & Shutdown called by "mammal team" \\
\hline $165 / 0017-0022$ & Shutdown called by "mammal team" \\
\hline $165 / 0314-0315$ & Shutdown called by "mammal team" \\
\hline $166 / 0329$ & End daylight operation with MCS \\
\hline $166 / 1200$ & Slow to deploy streamer and GI gun \\
\hline $166 / 1233$ & Begin daylight operations with MCS \\
\hline 166/1323-1324 & $\begin{array}{l}\text { Shutdown called by "mammal team" -(at 1324, system off } \\
\text { inside 3-mile limit) }\end{array}$ \\
\hline $166 / 1622-1630$ & Shutdown called by "mammal team" \\
\hline $166 / 1930-2013$ & GI gun shutdown at 3-mile limit (end of L245) \\
\hline $166 / 2047-2050$ & Shutdown called by "mammal team" \\
\hline $166 / 2054-2100$ & Shutdown called by "mammal team" \\
\hline $166 / 2150-2153$ & Shutdown called by "mammal team" \\
\hline $167 / 0135-0140$ & Shutdown called by "mammal team" \\
\hline
\end{tabular}


Table 2, continued

\begin{tabular}{|l|l|}
\hline $167 / 0323$ & End daylight operation with MCS \\
\hline $167 / 1210-1225$ & Slow to deploy streamer and GI gun \\
\hline $167 / 1232$ & Begin daylight operations with MCS \\
\hline $167 / 1458-1500$ & Huntec pulled out for inspect condition of streamers \\
\hline $167 / 1458-1520$ & Gl gun off to inspect for a slow leak in compressor \\
\hline $167 / 1758-1801$ & Shutdown called by "mammal team" \\
\hline $167 / 2053-2106$ & MCS off; 'blue screen death' by recording system \\
\hline $168 / 0323$ & End daylight operation with MCS \\
\hline $168 / 1218-1231$ & Slow to deploy streamer and Gl gun \\
\hline $168 / 1305$ & Begin daylight operations with MCS \\
\hline $168 / 1628$ & End daylight operation with MCS \\
\hline $168 / 1617-1643$ & $\begin{array}{l}\text { All gear recovered. End hazard survey activity. Change course and } \\
\text { come to full speed to head for site selected by Jon Childs for sound- } \\
\text { source measurements with calibrated hydrophone }\end{array}$ \\
\hline $168 / 1700-1720$ & Gear transfer to J. Childs on board the M/V LISA ANN (time approx.) \\
\hline $168 / 1740-1826$ & $\begin{array}{l}\text { Series of passes by M/V OCEAN OLYMPIC towing acoustic-source } \\
\text { on transect past Jon's calibration phone on the M/V LISA ANN using } \\
\text { the boomer sound source in Huntec. }\end{array}$ \\
\hline $168 / 1836-2000$ & Series of passes as above using the Gl gun on 10-sec. triggering \\
\hline $168 / 2001-2025$ & Series of passes as above using the Huntec sparker source \\
\hline $168 / 2028$ & $\begin{array}{l}\text { All gear on deck; both vessels change course and come to full speed } \\
\text { for Scripps Institution of Oceanography (SIO) Marine Facilities, San } \\
\text { Diego }\end{array}$ \\
\hline $168 / 2140$ & Dock at Scripps (SIO) Marine Facilities; end of cruise O1-99-SC \\
\hline
\end{tabular}


Table 3. Start and end times for 01-99-SC survey tracklines with multichannel seismic-reflection data (refer to web sites given in Table 4 for more details). Lines in italics are the doglegs between primary survey grid lines.

\begin{tabular}{|c|l|l|}
\hline Line number & $\begin{array}{c}\text { Start of line } \\
\text { (DDD/HHMM) }\end{array}$ & $\begin{array}{c}\text { End of line } \\
\text { (DDD/HHMM) }\end{array}$ \\
\hline L101 & $157 / 1504$ & $157 / 1733$ \\
\hline L102 & $157 / 1754$ & $157 / 2035$ \\
\hline L103 & $157 / 2122$ & $157 / 2328$ \\
\hline L104 & $157 / 2343$ & $158 / 0221$ \\
\hline L105 & $158 / 0245$ & $158 / 0333$ \\
\hline L114 & $159 / 1417$ & $159 / 1625$ \\
\hline L114DL & $159 / 1626$ & $159 / 1706$ \\
\hline L115 & $159 / 0039$ & $159 / 0134$ \\
\hline L116A & $158 / 2204$ & $158 / 2252$ \\
\hline L116B & $158 / 2309$ & $159 / 0010$ \\
\hline L116DL & $159 / 0015$ & $159 / 0038$ \\
\hline L118 & $158 / 1820$ & $158 / 2129$ \\
\hline L128 & $161 / 0044$ & $161 / 0317$ \\
\hline L161 & $167 / 0110$ & $167 / 0319$ \\
\hline L165 & $165 / 0214$ & $165 / 0323$ \\
\hline L170 & $167 / 1521$ & $167 / 1728$ \\
\hline L200 & $158 / 1226$ & $158 / 1707$ \\
\hline L200DL & $158 / 1716$ & $158 / 1815$ \\
\hline L202 & $159 / 1706$ & $159 / 1755$ \\
\hline L202B & $159 / 1800$ & $159 / 2203$ \\
\hline L202DL & $159 / 2213$ & $159 / 2300$ \\
\hline L203 & $159 / 2318$ & $160 / 0335$ \\
\hline L204 & $160 / 1320$ & $160 / 1745$ \\
\hline L204DL & $160 / 1747$ & $160 / 1837$ \\
\hline L204DM & $160 / 1847$ & $160 / 1927$ \\
\hline L205 & $160 / 1929$ & $160 / 2353$ \\
\hline L205DL & $160 / 2353$ & $161 / 0040$ \\
\hline L213 & $161 / 1335$ & $161 / 2048$ \\
\hline L215 & $161 / 2134$ & $162 / 0051$ \\
\hline L217 & $162 / 1420$ & $162 / 1806$ \\
\hline L219 & $162 / 1847$ & $162 / 2315$ \\
\hline L219DL & $162 / 2317$ & $162 / 2359$ \\
\hline L221 & $163 / 0010$ & $163 / 0326$ \\
\hline L221B & $163 / 1257$ & $163 / 1447$ \\
\hline L223 & $163 / 1540$ & $163 / 1926$ \\
\hline L223DL & $163 / 1933$ & $163 / 2012$ \\
\hline L225 & $163 / 2012$ & $163 / 2318$ \\
\hline L225B & $163 / 2324$ & $164 / 0016$ \\
\hline L227 & $164 / 0101$ & $164 / 0322$ \\
\hline & & \\
\hline &
\end{tabular}




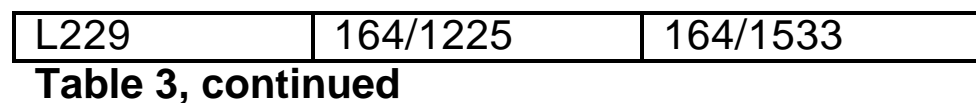

\begin{tabular}{|l|l|l|}
\hline L231 & $164 / 1626$ & $164 / 2036$ \\
\hline \multicolumn{1}{|c|}{ L231DL } & $164 / 2044$ & $164 / 2117$ \\
\hline L233 & $164 / 2118$ & $165 / 0140$ \\
\hline L237 & $165 / 1227$ & $165 / 1605$ \\
\hline L239 & $165 / 1645$ & $165 / 2220$ \\
\hline L239DL & $165 / 2231$ & $165 / 2259$ \\
\hline L241 & $165 / 2259$ & $166 / 0322$ \\
\hline L241B & $166 / 1239$ & $166 / 1323$ \\
\hline L242 & $167 / 1233$ & $167 / 1457$ \\
\hline L243 & $166 / 1405$ & $166 / 1630$ \\
\hline \multicolumn{1}{|c|}{ L243DL } & $166 / 1635$ & $166 / 1708$ \\
\hline L245 & $166 / 1708$ & $166 / 1930$ \\
\hline L247 & $166 / 2013$ & $167 / 0035$ \\
\hline L247DL & $167 / 0044$ & $167 / 0108$ \\
\hline L248 & $168 / 1510$ & $168 / 1617$ \\
\hline L249 & $167 / 1744$ & $167 / 1914$ \\
\hline L250 & $168 / 1305$ & $168 / 1427$ \\
\hline \multicolumn{1}{|c|}{ L250DL } & $168 / 1432$ & $168 / 1503$ \\
\hline L251 & $167 / 2000$ & $167 / 2053$ \\
\hline L251B & $167 / 2106$ & $167 / 2128$ \\
\hline L253 & $167 / 2213$ & $168 / 0019$ \\
\hline L255 & $168 / 0101$ & $168 / 0224$ \\
\hline N905 & $157 / 1354$ & $157 / 1450$ \\
\hline \multicolumn{1}{|c|}{$N 905 D L$} & $157 / 1450$ & $157 / 1504$ \\
\hline N913 & $159 / 1230$ & $159 / 1232$ \\
\hline N913B & $159 / 1239$ & $159 / 1340$ \\
\hline N916 & $160 / 1233$ & $160 / 1249$ \\
\hline \multicolumn{1}{|c|}{$N 916 D L$} & $160 / 1249$ & $160 / 1254$ \\
\hline N920 & $161 / 1232$ & $161 / 1312$ \\
\hline N925 & $162 / 1246$ & $162 / 1326$ \\
\hline N943 & $168 / 0229$ & $168 / 0319$ \\
\hline & & \\
\hline
\end{tabular}




\section{Table 4. Locations of cruise data}

Operational details of this cruise, including digital navigation and bathymetry files, are available with accompanying metadata through the USGS Western Region Coastal and Marine Geology (WRCMG) web site given below. After accessing the site, Click on Table of Contents;

Click on Infobank;

Click on ship (O for M/V OCEAN OLYMPIC), or year (99 for 1999), or region (SC for Southern California);

Navigate to the O-1-99-SC metadata site;

Click on underlined words to find cruise information and data.

Web site:

\begin{tabular}{|l|l}
\hline General cruise & http://walrus.wr.usgs.gov
\end{tabular}
operational information:

Within this report:

\begin{tabular}{|l|l|}
\hline Table 1 & O1-99-SC scientific party and ships crew \\
\hline Table 2 & Operational log \\
\hline Table 3 & Trackline start/end times for multichannel seismic-reflection data \\
\hline Table 4 & Locations of cruise data \\
\hline Appendix 1 & Cascadia Research Collective report on marine mammals \\
\hline
\end{tabular}

(See also Appendix 1 for report of mammal observers.) 


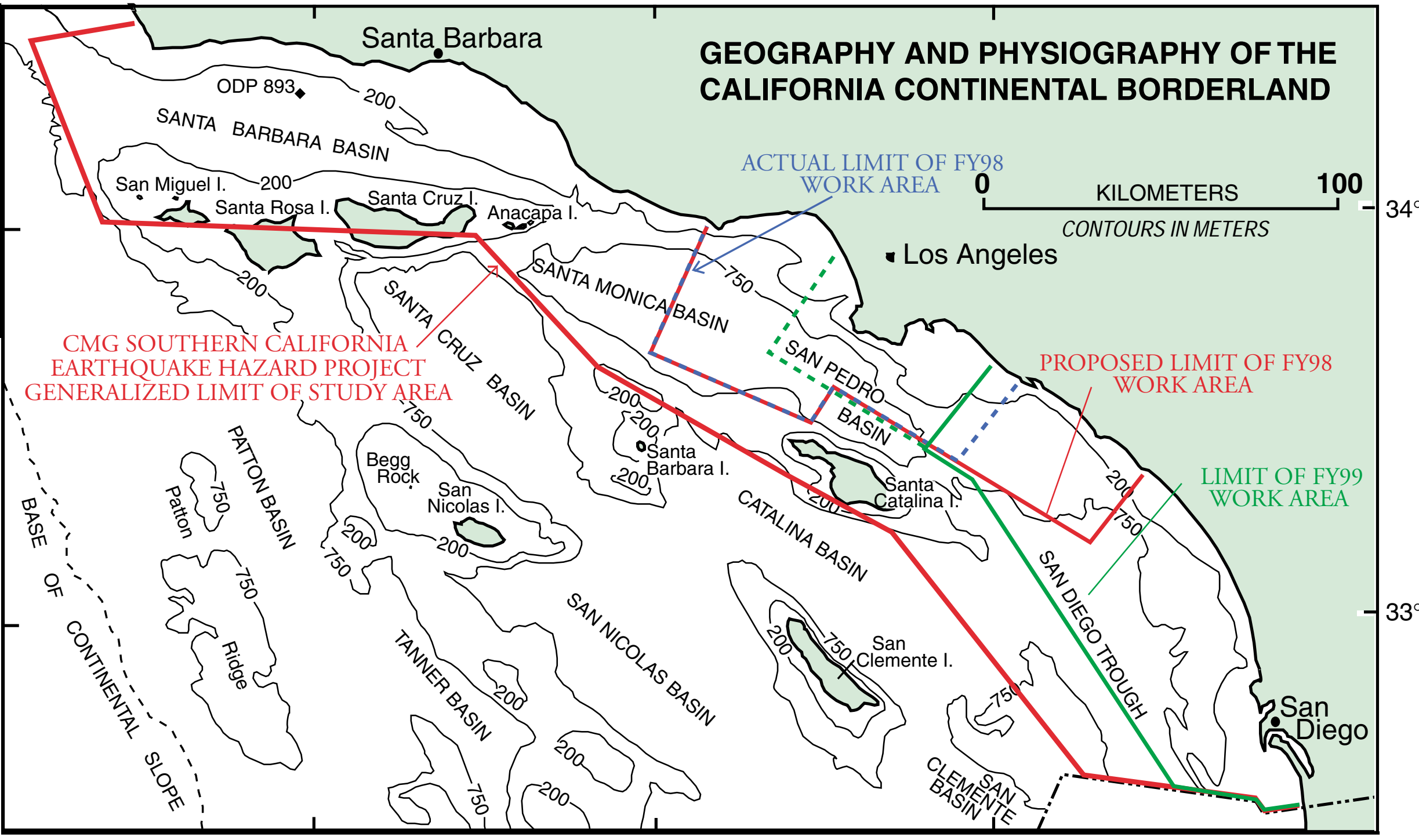




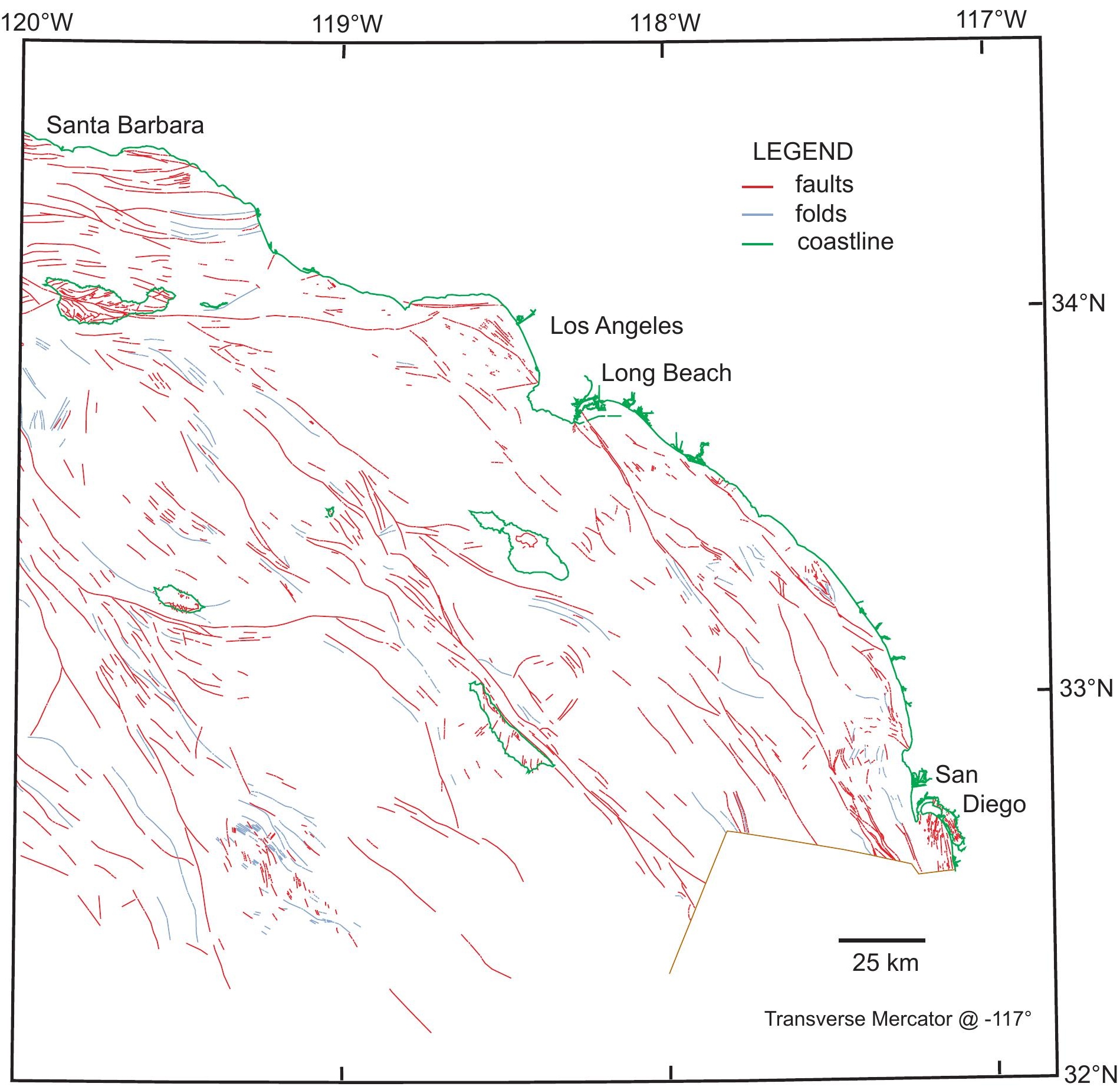




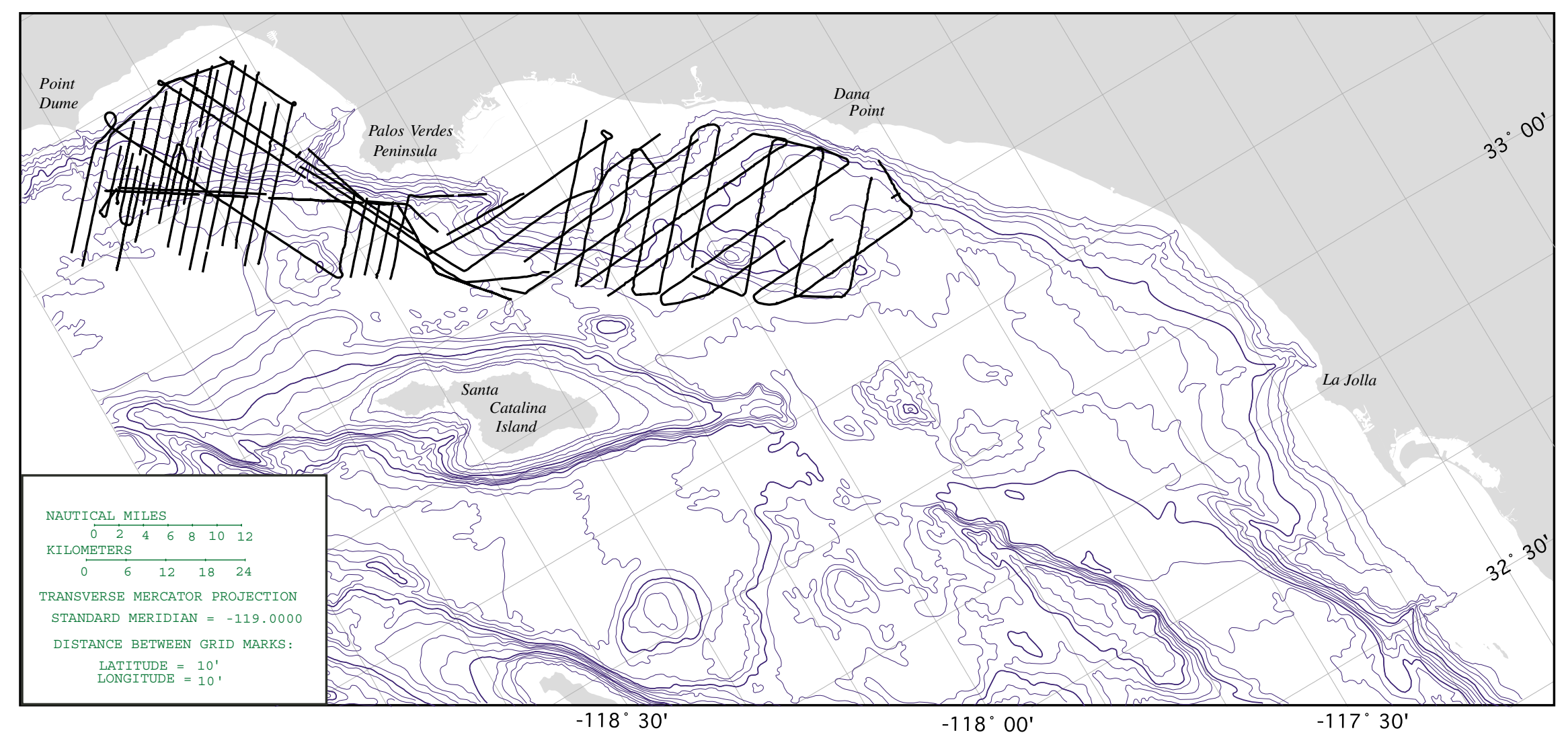




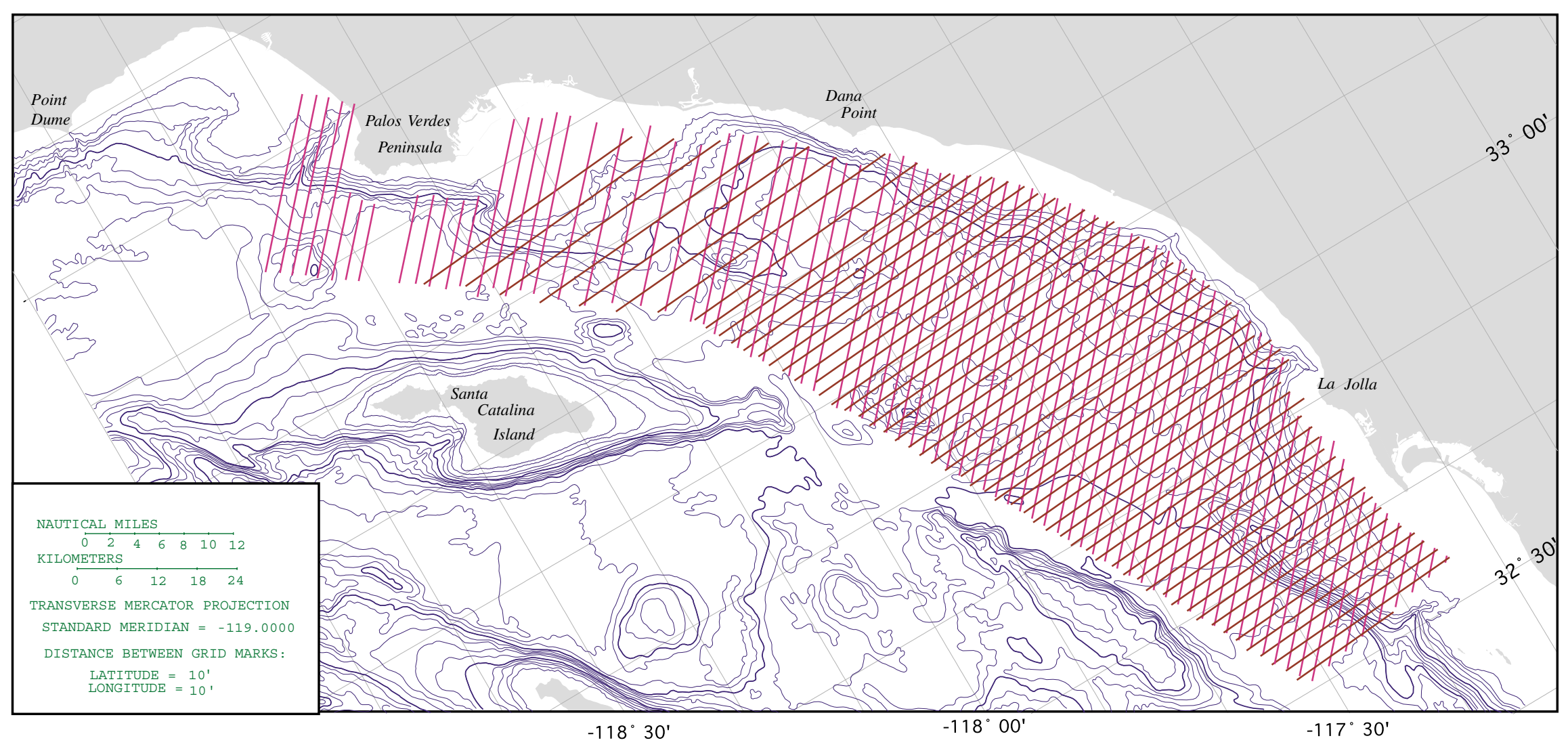




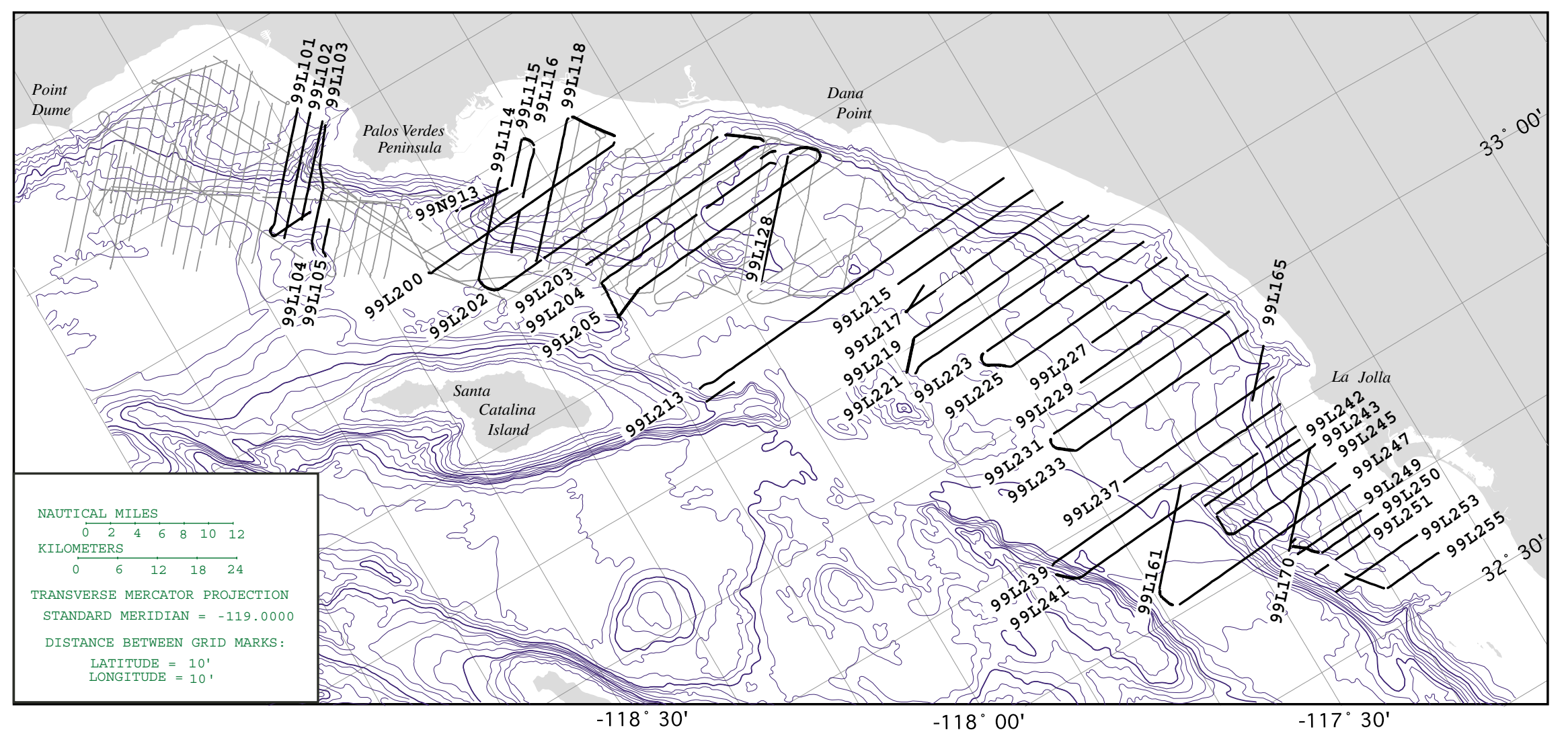




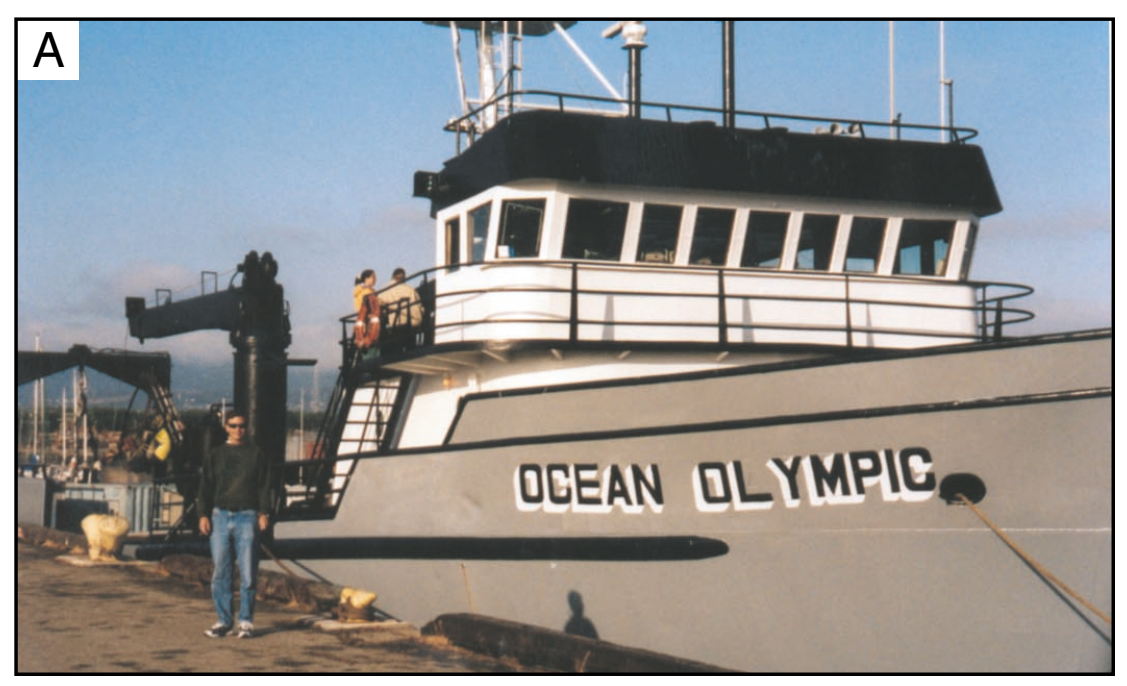

FIGURE 5
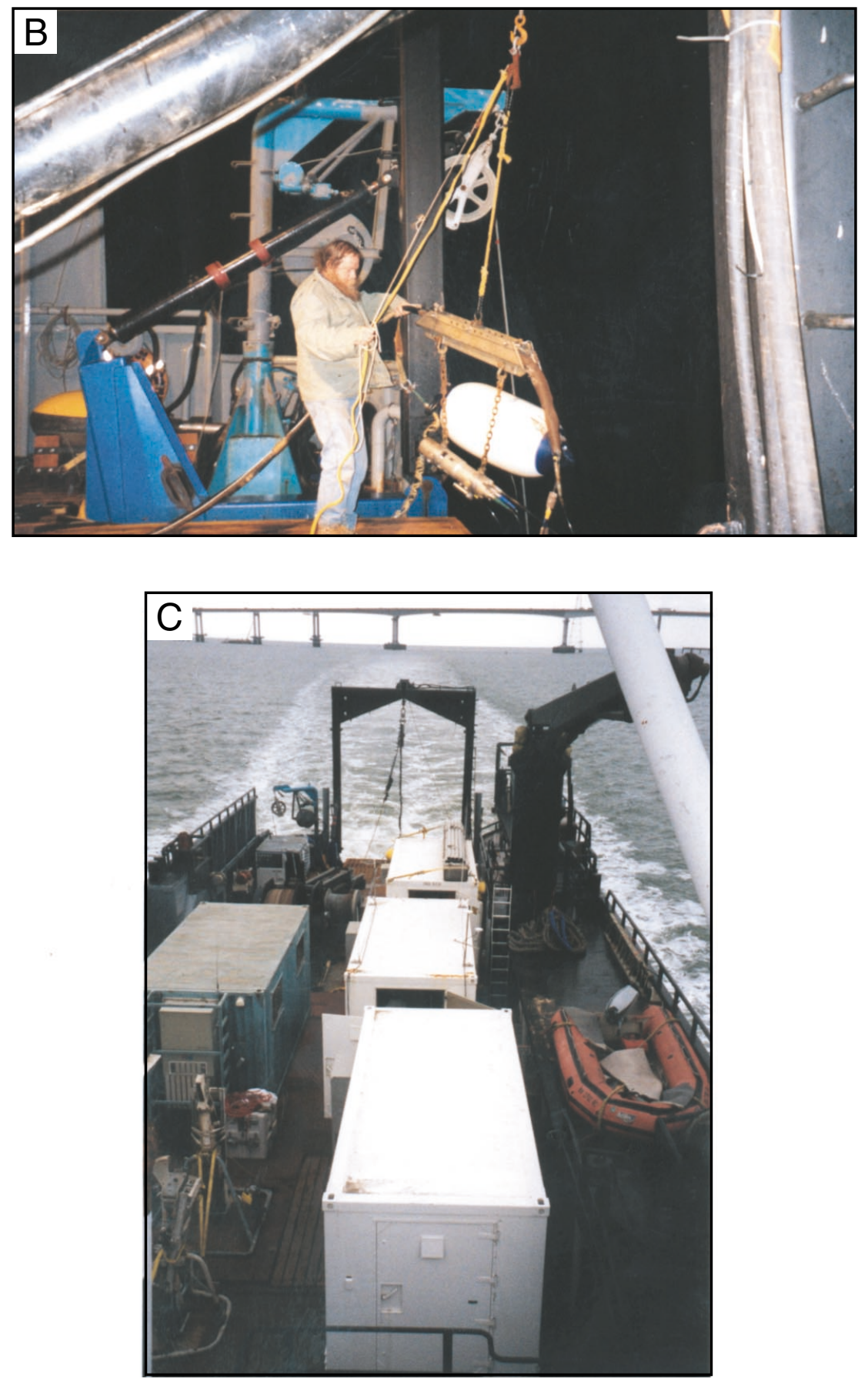
A

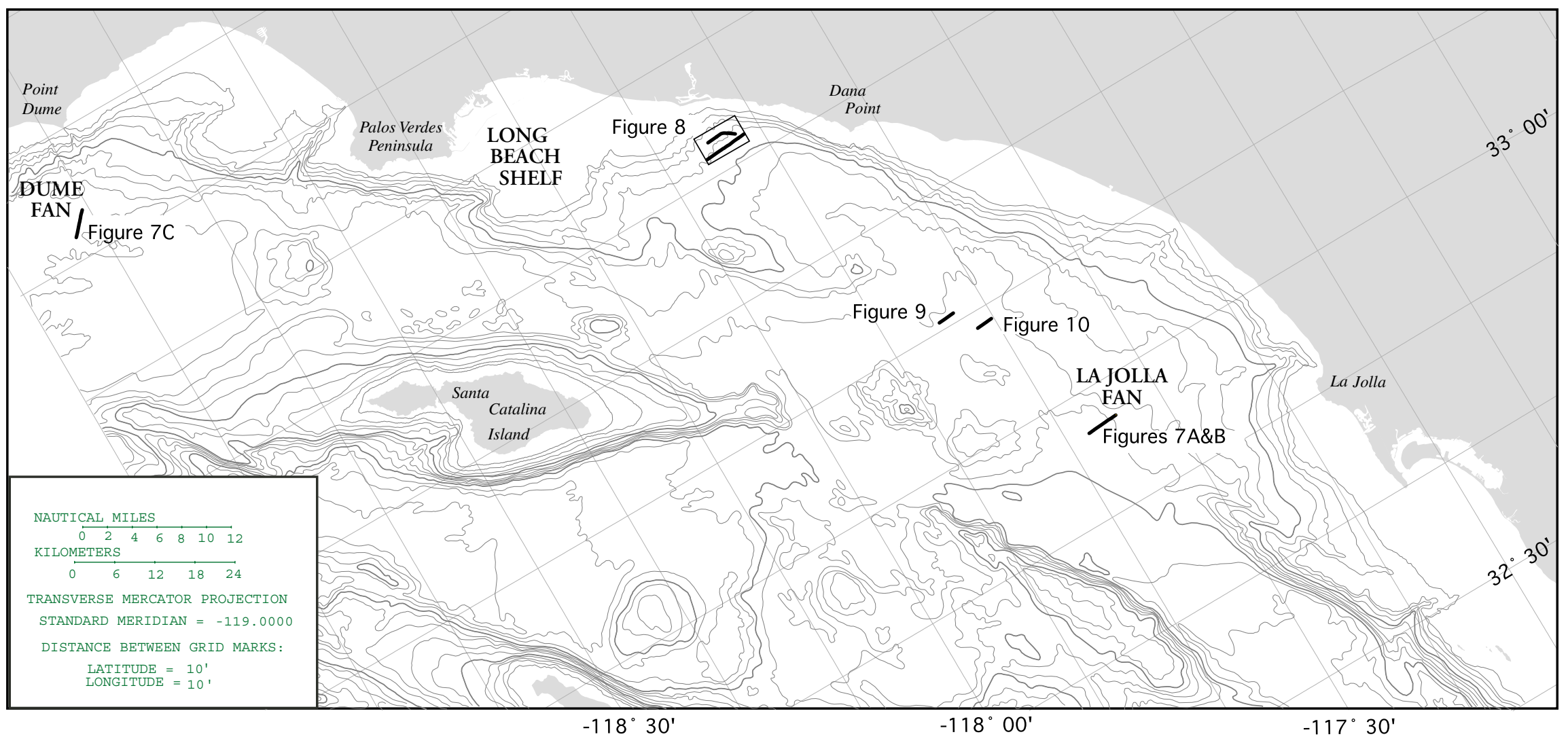

B

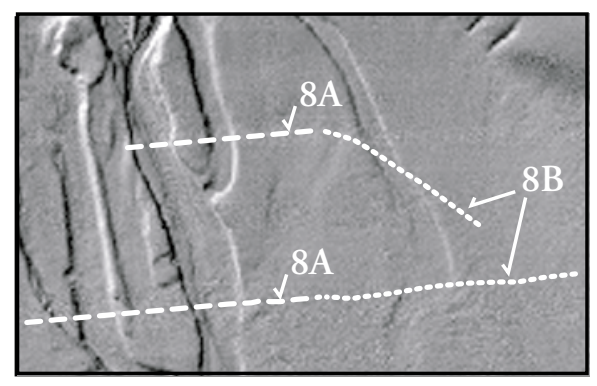

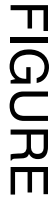


FIGURE 7
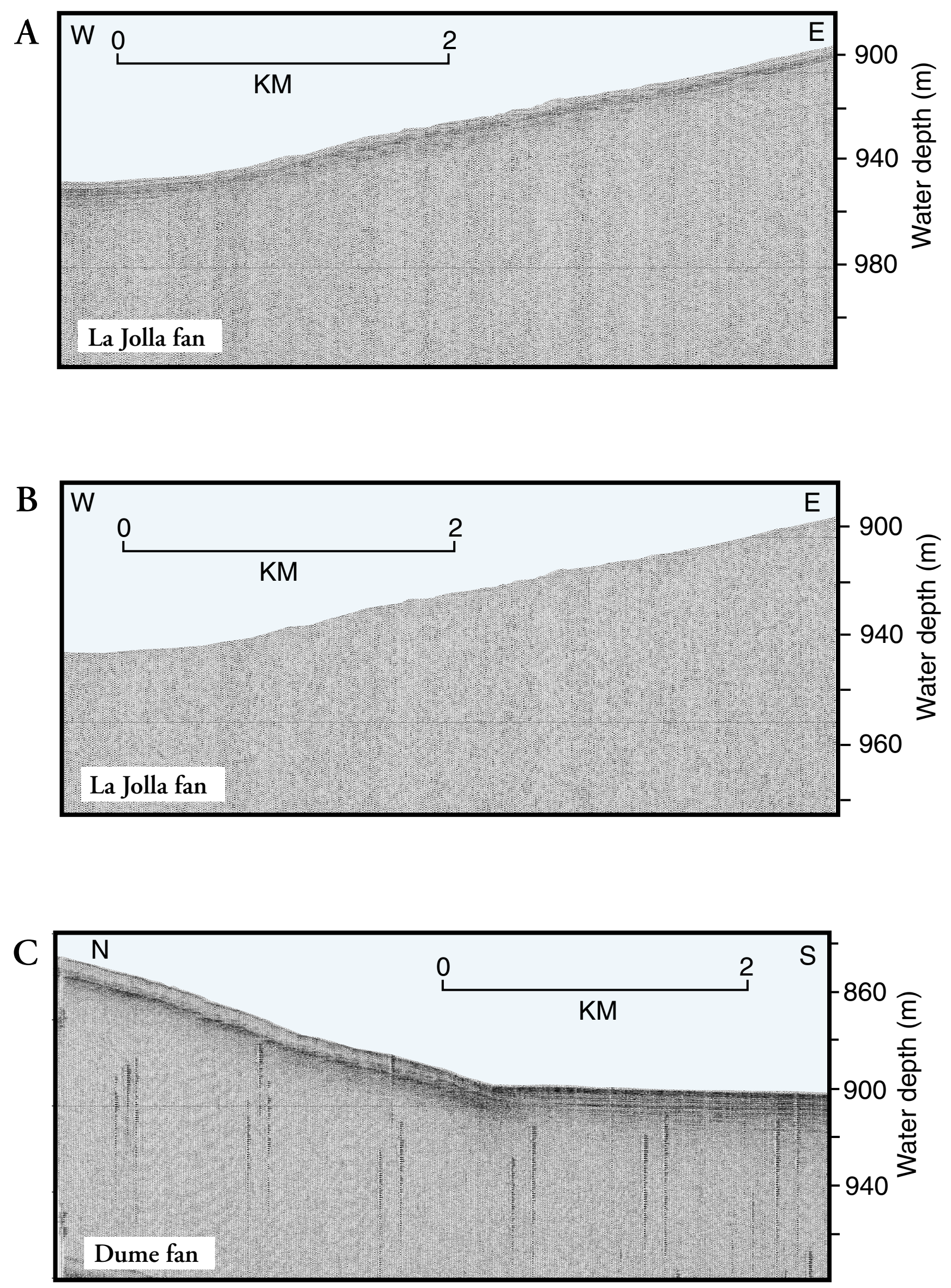

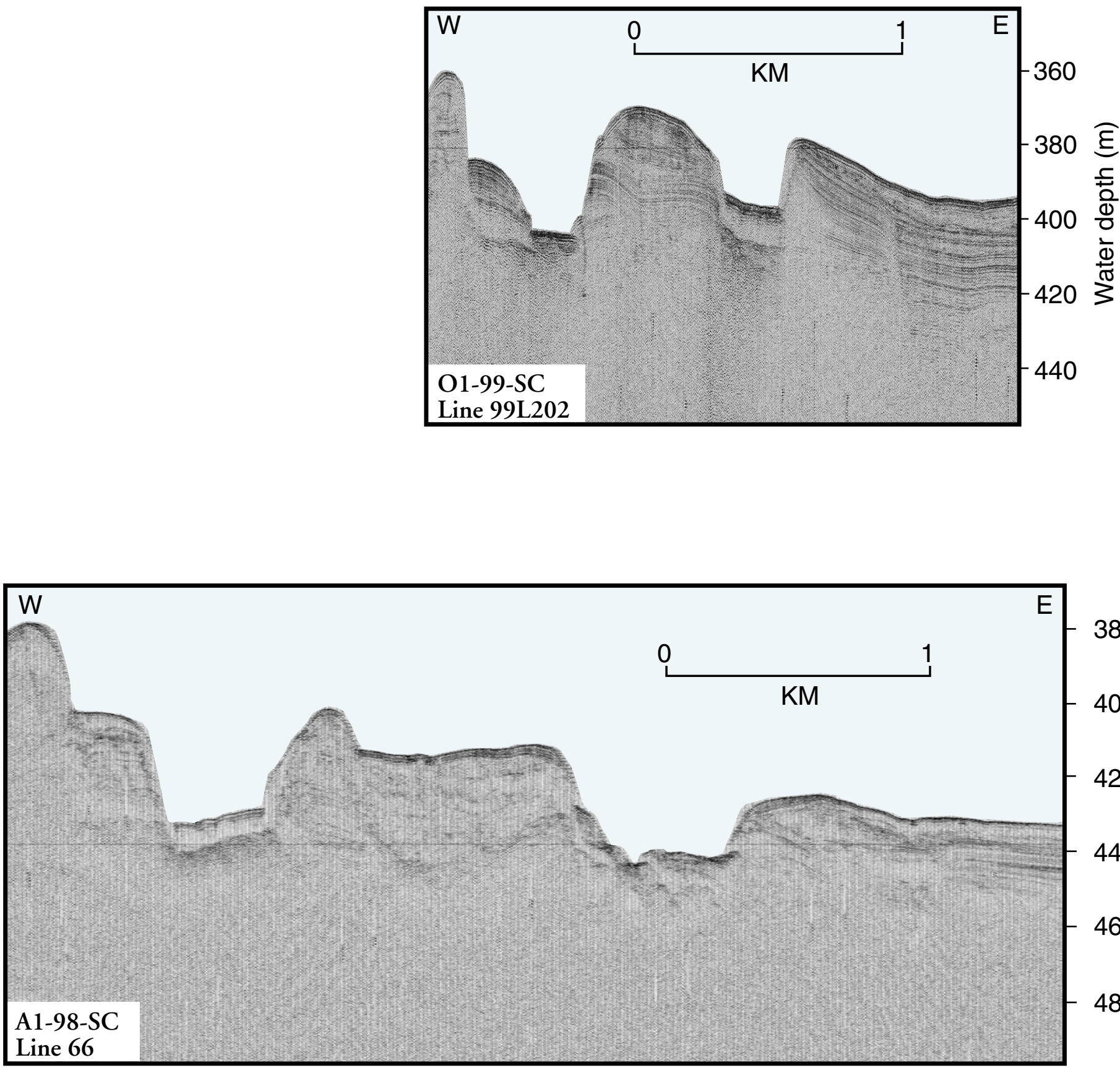

E 
FIGURE 8B
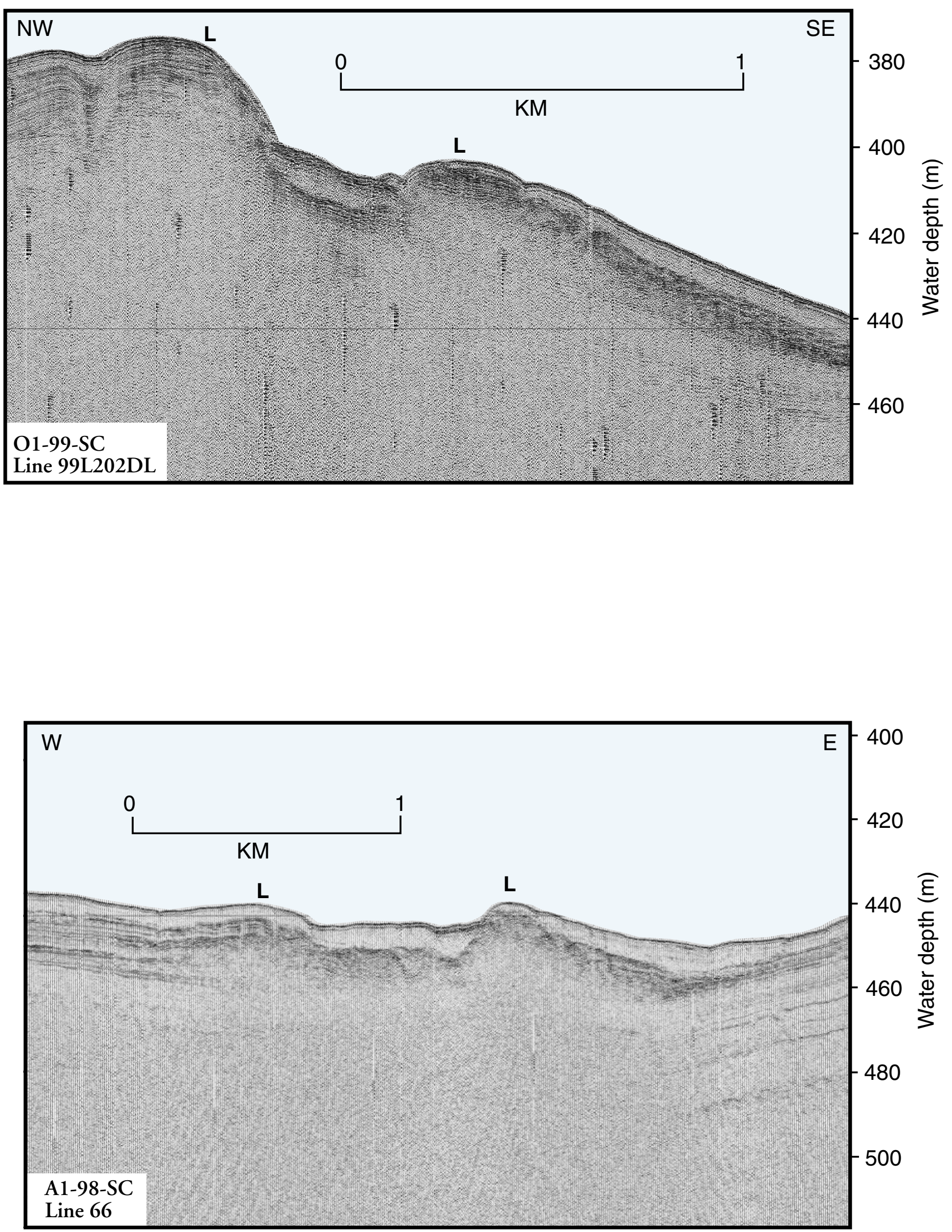


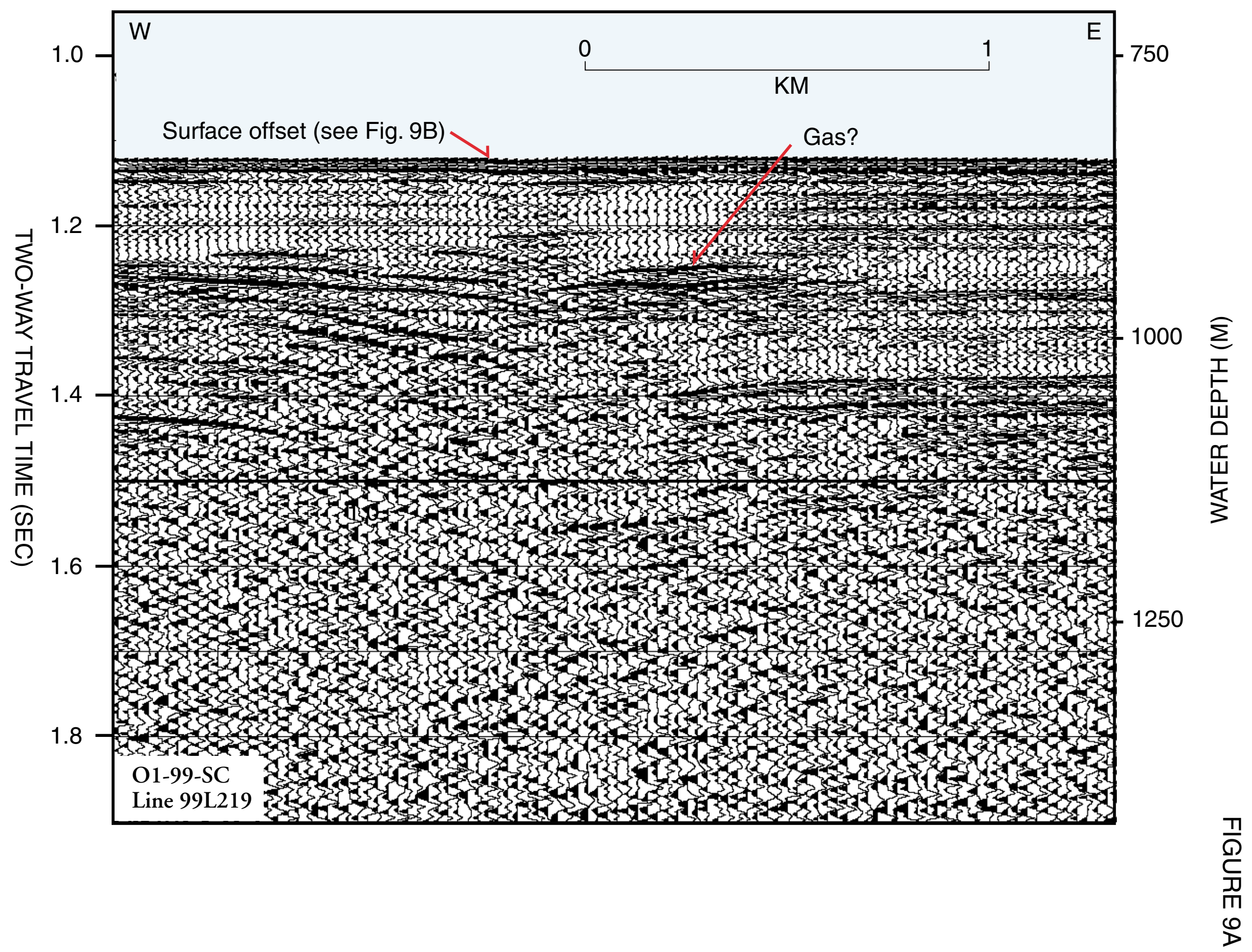


FIGURE 9B

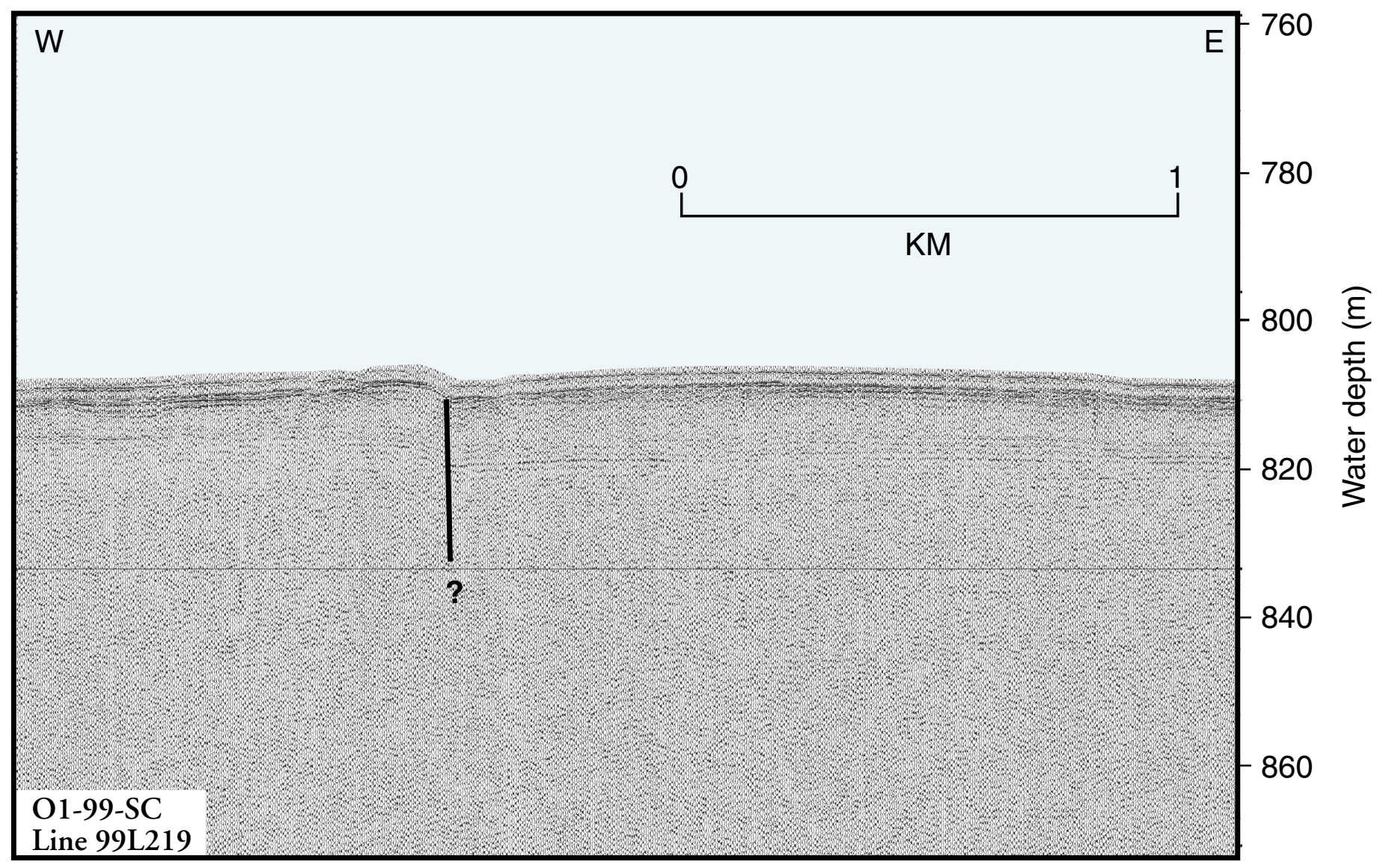




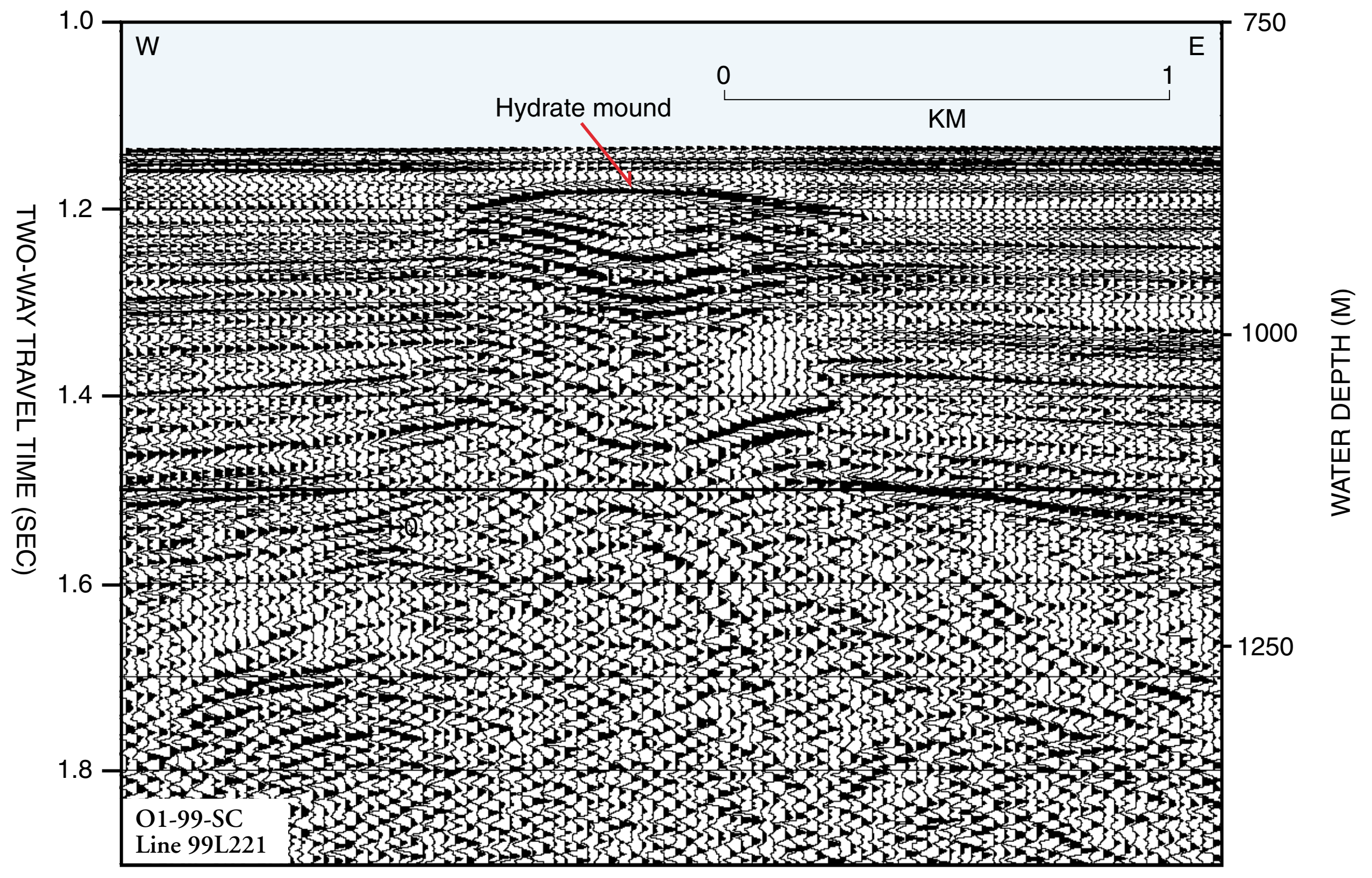




\section{Appendix 1}

USGS OFR 99-560

Report prepared by Cascadia Research Collective under contract to the USGS in support of Cruise 01-99-SC (as required by National Marine Fisheries Service for the Incidental Harassment Authorization issued to the USGS) 
FINAL REPORT

MARINE MAMMAL OBSERVATIONS AND MITIGATION ASSOCIATED WITH USGS SEISMIC SURVEYS IN THE SOUTHERN CALIFORNIA BIGHT IN 1999

\author{
Prepared for \\ U.S. Geological Survey \\ 345 Middlefield Rd. \\ Menlo Park CA 94025
}

\author{
Prepared by \\ Jennifer Quan \\ John Calambokidis
}

Cascadia Research 218 W Fourth Ave.

Olympia, WA 98501

September 1999 


\section{ACKNOWLEDGEMENTS}

A number of people and organizations assisted in this project. Tamara Gunther and Annie Douglas conducted marine mammal observations from the Ocean Olympic. The captain and crew of the Ocean Olympic were very helpful, providing technical assistance, comfort, and company throughout the survey. The U.S. Geological Survey provided funding for this project.

\section{INTRODUCTION}

From 6 to 17 June 1999 (4 to 5 June were transit days), the U.S. Geological Survey conducted seismic-reflection surveys in the coastal waters of the Pacific Ocean, between Los Angeles and San Diego, to investigate earthquake hazards. As a part of this project, Cascadia Research was contracted by the USGS to monitor marine mammals from the survey platform and provide mitigation on impacts on marine mammals by requesting shutdown of the sound sources when marine mammals were close to the operations.

This report summarizes the results of a marine mammal mitigation and monitoring program conducted in conjunction with these USGS surveys and adds information to similar work conducted by Cascadia Research in 1998 (Calambokidis et al 1998b). There were several modifications to observations and mitigation operations made for the 1999 survey from that in 1998: 1) Three observers were on board with two on duty during daylight observations, 2) the mitigation safety zone was extended from 200 meters to 250 meters for baleen and sperm whales, and 3) airgun operations during the night time hours were suspended.

\section{BACKGROUND ON OVERALL PROJECT AND SOUND SOURCE DESCRIPTION}

The following background on the overall project and sound source description was provided by USSGS:

The focus of this project is to identify the landslide and earthquake hazards, as well as related deformation processes, that have great potential to impact the social and economic well being of the inhabitants of the Southern California coastal region--the most heavily populated urban corridor along the U.S. Pacific margin. We are studying Pleistocene-Holocene sedimentation and deformation patterns and related seismicity and strain within the coastal zone and adjacent continental borderland basins. Our findings will help us evaluate the hazard potential for large, destructive earthquakes and identify how deformation is distributed in space and time between onshore and offshore regions. The results of this project will contribute to decisions involving land use, hazard zonation, and building codes in the area.

The active field program for the project focuses on those areas with the greatest impact potential on the Southern California populace: 
1) The coastal strip (coastal zone and continental shelf) between Los Angeles and San Diego, where much of the hazard appears to be associated with strike-slip or oblique-slip faults;

2) Active faults within the Santa Monica, San Pedro, and San Diego Trough basins, where more extensive sedimentation has left a greater stratigraphic record;

3) The offshore extension into the Santa Barbara Channel of the fold and thrust belt;

4) The boundary (Channel Islands region) between the inner California Borderland (strike-slip dominated deformation) and the Santa Barbara Channel (thrust and fold deformation).

Tracklines were planned at a $2 \mathrm{~km}$ spacing aligned perpendicular to the shelf break and basin slope and on an "orthogonal" set aligned to intercept major structural features that are oblique to the trend of the basin slope and shelf edge. For the FY 1999 , only one set of tracklines was attempted because of time limitation on hours of operation. As a result, generally only every other line was run, i.e., the grid was $4 \mathrm{~km}$ spacing with only one set of the planned grid over most of the area.

The FY 1999 field program was conducted using a leased vessel, the 156-ftlong M/V OCEAN OLYMPIC, owned and operated by F/V NORTH WIND INC.

Two sound transmissions were used:

Huntec: A high-resolution Huntec DTS boomer system, towed between $6 \mathrm{~m}$ and $160 \mathrm{~m}$ below the sea surface (depending upon the water depth), was used to image the upper few tens of milliseconds of strata with a resolution of better than $0.5 \mathrm{~ms}(0.4$ $\mathrm{m})$. Power output was 350 Joules (540) with a firing rate that was also dependent on water depth, ranging from $0.4 \mathrm{sec}$ over the shelf and upper basin slopes to $1.3 \mathrm{sec}$ over the shelf and upper basin slopes to $1.25 \mathrm{sec}$ over the deeper parts of the basins. Returning signals were received with a $7.6 \mathrm{~m}$ long 25-element hydrophone array. Signals were filtered at $700-8000 \mathrm{~Hz}$ and recorded at a $0.25 \mathrm{sec}$ sweep. The data were recorded both on paper using an EPC recorder and on magneto-optical disc.

Multichannel seismic-reflection system (MCS): The sound source used during this years survey was a $35 / 35$ in 3 double-chamber GI gun firing every 12 seconds at a pressure of about 3000 psi. A Sureshot system was used to fire the gun in "harmonic mode" wherein the second chamber is delayed relative to the initial trigger pulse in order to achieve the cleanest signal by minimizing the bubble pulse. The Gl gun was towed 12 meters behind the vessel and suspended from a float to maintain a depth of about 1 meter.

The streamer used for the MCS operation was a 24-channel ITI streamer with 10 -m-long groups and 3 phones per group.

\section{OBJECTIVES}

The objectives of the marine mammal study were as follows: 
1. Mitigate impacts on marine mammals by monitoring the presence of these species from the survey ship and requesting shut-down of the airgun array when marine mammals were seen within specified safety zones representing distances close enough to potentially cause physical injury.

2. Document the number of animals of each species present in the vicinity of sound transmissions.

3. Evaluate the reactions of marine mammals to the sound transmissions at different distances from the airgun array.

4. Conduct limited tests of night vision equipment.

\section{METHODS}

\section{General Approach}

The research effort consisted of observations made directly from the survey vessel (Ocean Olympic) to provide mitigation, document marine mammals exposed to the airgun during daylight hours, and monitor reactions of marine mammals close to the seismic-reflection survey vessel. Three observers were placed on board the vessel and observations were conducted from the bridge deck that put the observers eye level at $7.8 \mathrm{~m}$ above the water. This external platform provided good mobility and a clear view from the front, sides and rear of the vessel. The observation platform was near the front of the vessel $7.2 \mathrm{~m}$ behind the bow and $47 \mathrm{~m}$ from the stern of the vessel.

Observations were conducted from the fishing vessel (Ocean Olympic), during a short transit period (between June 4 and 5) and in the daylight when seismic-reflection operations were underway. While the seismic-reflection operations were underway observations began within a half hour of sunrise, when lighting conditions allowed for the sightings to be made within the mitigation zones and ended within an half an hour after sundown, when lighting conditions became too dark for sightings to made within the mitigation zone. During the daylight observation periods, two observers stood watch, one on the port and the other the starboard. The third observer would rotate in every two hours. Generally, each observer worked shifts of four hours on and two hours off (averaging about 11 hour per day). Observers used Tasco $7 \times 50$ binoculars with internal compasses and reticles to record the horizontal and vertical angle to sightings.

Data on survey effort and sightings were recorded on a datasheet recording information to track survey effort which includes observers on duty and weather conditions (Beaufort sea state, wind speed, cloud cover, swell height, precipitation, visibility, etc.). For each sighting, the time, bearing and reticle reading to sighting, species, group size, surface behavior, and orientation were recorded.

Distances to sightings were calculated using the vertical angle to the animal (based on either the reticle reading through the binoculars or a hand help clinometer 
for close sightings) and the known elevation above the water. This was then used to evaluate whether a sighting was within the mitigation safety zones.

\section{Mitigation safety zones}

Two safety zones were used for this project. These were:

1. For pinnipeds and odontocetes (all toothed cetaceans except sperm whales) seismic operations would be shut down when an animal was seen close to a distance of $100 \mathrm{~m}$ or less.

2. For mysticetes (baleen whales) and sperm whales, the safety zone was $250 \mathrm{~m}$.

To allow a quick determination of status, safety zones were calculated in three arcs around the ship and the safety distance was applied using the closest part of the ship or array. Three different cut-off distances (based on distance and angle from the observers) were calculated for off the bow (60 degrees to either side of the bow), to either side of the vessel (from 60 to 120 degrees off the bow and off the stern (120 to 180 degrees off the bow).

Observers were instructed to call for a shut-down when a marine mammal was seen inside the safety zone or close enough to the safety zone that given measurement-error, it could be within the safety zone. Shut-down was also considered when animals were ahead of the vessel path outside the safety zone, but it appeared likely that the direction of travel of the vessel would result in the marine mammal being within the safety zone shortly. Marine mammals were tracked until they were outside the safety zone at which time seismic-reflection operations resumed.

For effective mitigation, the observers needed to know very quickly whether a sighting was within the safety zone. We used a polaris (angle board) for the observers to estimate the angle to the sighting. The cut-off vertical angle, which represented each of the safety zones, was also written on the polaris, allowing quick determination of the proximity of a sighting to the safety zone.

\section{Night Observations}

A total of 6 hours and 36 minutes, over the span of seven nights, was devoted to night observations. Two different sets of night vision viewers supplied by USGS were tested (ITT night vision binoculars model 200/210 and model 250/260). Night observations were conducted by one observer and took place from the bridge, bridge wings and bridge deck. Observations were limited toward the front of ship to 95 degrees either side of the bow, as deck lights on the stern of the vessel created light conditions (too bright) that were not conducive for viewing with the night vision viewers. Observations were conducted in weather conditions that ranged from $0 \%$ cloud cover to $100 \%$, and in Beaufort sea states ranging from 1-5. Two sightings of common dolphin were recorded during night observations, both occurring on the evening of 6 June 1999. The first sighting was a "re-sight" of animals originally observed during daylight observation operations. Both observations were made by "naked-eye", and as the dolphins approached the ship to ride the bow waves and 
wake waves made by the vessel. No sighting of marine mammals were made with the aid of either night scope.

\section{RESULTS AND DISCUSSION}

\section{Marine mammal mitigation - Shut-downs}

Shut-down of the airgun was called for in 21 instances during the daylight observations (Table 1). In all shut-down cases both the airgun and the Huntec were in firing operation. Seventeen of the shut-downs were for common dolphin (in seven of these shut-downs the dolphins approached the ship to bow ride) and in one of the shut-downs the dolphins where associated with a California sea lion. The other shutdowns requested were: one for a California sea lion, one for an unidentified pinniped, one for a large baleen whale (sei whale or fin whale), and one for a group of Pacific white-sided dolphin (which approached the ship to bow ride). Shut-downs lasted anywhere from less than one minute to 13 minutes. Twelve of the shutdowns were called when the animal was just outside the safety zones but appeared likely to be within the safety zone shortly, and nine shut-downs were called when the animals were seen already within the safety zones.

\section{Marine mammal sightings}

There were a total of 181 sightings (not including re-sightings), comprised of 13,486 marine mammals encountered during observation operations (Table 2) and more than half $(60 \%)$ of the sightings were made while the airgun and Huntec were in operation (Table 3). Some of these groups were seen more than one time, and account for 156 re-sightings. Nine species of marine mammals made up these sightings. Humpback whales and Dall's porpoise were seen only in the transit area (from roughly San Francisco to just north of Los Angeles - during which time no seismic-reflection equipment was deployed). Within the survey area, common dolphin, blue whales, and California sea lions were the most frequently observed. Other large whale species included a number of unidentified whales, one of, which was likely to be either a sei or fin whale. Other small cetaceans included Risso's dolphin, Pacific white-sided dolphin, and one sighting of bottlenose dolphin. Sightings of unidentified dolphin were likely to be either common dolphin or Pacific white-sided dolphin. Beside California sea lions, no other pinnipeds were positively identified.

\section{Orientation and behavior of marine mammals in relation to firing status of seismic equipment}

Marine mammals were observed moving in all directions in relation to the heading of the vessel (Table 4). Sightings of animals seen while both the airgun and Huntec were firing tended to be slightly more towards $(22 \%)$ than away $(11 \%)$ and the re-sightings slightly more away (23\%) than towards (15\%). A large portion of the animals observed moving towards the ship, during these times, were common dolphin which are well known for approaching ships to ride the bow wake, and which may 
account for the higher number of animals seen moving toward the ship when initially sighted. Some of these groups did approach the ship to bow ride and when ceased bow riding were re-sighted moving away from the ship which may account for the higher number of animals observed moving away when re-sighted. Overall there were no major differences in the movements observed in relation to firing status of the airgun and Huntec or when the equipment was not firing at all. Further, it is not possible to determine if any of the observed movements could be attributed to marine mammals reacting to the seismic equipment.

Marine mammals were observed exhibiting a variety of behaviors (Table 5). The most common behaviors that were observed were classified as slow or fast travel. Other common behaviors were milling, which can indicate feeding activity, porposing (California sea lions), and bow riding (common dolphins, Pacific white-sided dolphin, and Dall's porpoise). Less common behaviors included slow rolling, breaching, fluke diving, medium travel, and hauled, splashing and vertical sinks (the last three behaviors describe those associated only with pinnipeds). It is not possible to determine if any of these activities could have been related to the seismic-reflection operations.

\section{Night Observations}

The objective of the night observations was to test the utility of night vision viewers as a tool for observing for and detecting marine mammals at night. Of the two sets of viewers used, the Viewer 200/210 was favored for its consistent clarity and focus, while the Viewer 250/260 was highly variable in its over all performance, was too grainy, and did not hold it's focus. While the Viewer 200/210 provided some assistance in night observations it was limited by the following factors:

- Distance Detection - There are no methods for determining distance (as with reticule binoculars) while observing through the scope, and observers felt that confidence in estimating distance in the dark and while observing through the viewers did not extend beyond 100 meters.

- Field of View - The field of view is limiting, allowing roughly, only a span of 40 degrees to be observed at a time.

- Ambient light conditions - Ambient light conditions may have an affect on sighting ability. Conditions seem to improve when some ambient light is present, as with water lit by a cityscape or moon light. In conditions of complete darkness/ cloud cover, the possibility of detection seems lower, as not even the horizon is visible.

- Lights from the Observation Vessel - Deck lights on the stern of the ship were too bright, and made observation around the sound source itself impossible.

- Sea State - Observation of the dolphins made with the viewers, on 6 June 1999, were in Beaufort 3 conditions. The animals were only distinguishable from white caps when within roughly 6 meters of the bow. 
- Physical Constraints - The viewers where physically constraining, allowing the observer to safely move around at a slow speeds, and use of the goggle for an hour produced eye strain for some of the observers.

\section{DISCUSSION AND CONCLUSIONS}

Shut-downs were more common in 1999 compared to 1998. Most of the shutdowns were related to common dolphins. This species was sighted more times in 1999 than during the 1998 surveys. Surveys were conducted slightly earlier in the year in 1999 and also covered a slightly different area. Either of these or the annual differences in oceanographic conditions could have been responsible for the higher number of sightings of this species and resultant higher shut-downs. This species often approaches the boat to bow ride thus causing the high number of shut-downs when this species was encountered.

There were also larger numbers of baleen whales encountered in 1999 compared to 1998. Some of these sightings, including those of humpback whales were primarily made while the vessel was in transit to the study area prior to airgun operations. Sightings of blue whales were still far more common within the study area during airgun operations in 1999 compared to 1998; 15 sightings were made in 1999 during operations compared to only 3 in 1999 (includes possible fin whales). Again the timing of the surveys or inter-annual oceanographic changes could have been responsible for the differences.

Marine mammal movements and behaviors observed during the seismicreflection operations, revealed no apparent patterns of avoidance and none could be interpreted as harassment.

No sightings were made with the aid of the night vision viewers, and therefore the utility of the night vision viewers as a tool for detecting marine mammals at night is difficult to determine. This assessment of night observations operations has revealed that for night observations to be marginally effective while using the night vision viewers requires:

- Methods for detection of distance would need to be established

- Viewing conditions would have to have some level of ambient light

- Deck lights on the stern of the ship would have to be dimmed or extinguished

- Sea State conditions would have to be at a Beaufort three or lower

- To compensate for the 40 degree field of view, at least three observers per shift would be needed.

- Observation shifts no longer than two hours to allow for relief of eye strain, or until the observers eyes adjust to such sighting conditions. 


\section{REFERENCES}

Calambokidis, J. and G.H. Steiger. 1995. Population estimates of humpback and blue whales made through photo-identification from 1993 surveys off California. Report to Southwest Fisheries Science Center, National Marine Fisheries Service, La Jolla, California. 36pp.

Calambokidis, J. and G.H. Steiger. 1997. Blue Whales. Worldlife Series Library. Voyager Press, MN. 72 pp.

Calambokidis, J., G.H. Steiger, J.R. Evenson, K.R. Flynn, K.C. Balcomb, D.E. Claridge, P. Bloedel, J.M. Straley, C.S. Baker, O. von Ziegesar, M.E. Dahlheim, J.M. Waite, J.D. Darling, G. Ellis, and G.A. Green. 1996. Interchange and isolation of humpback whales off California and other North Pacific feeding grounds. Marine Mammal Science 12:215-226.

Calambokidis, J., T. Chandler, K. Rasmussen, G.H. Steiger, and L. Schlender. 1998a. Humpback and blue whale photographic identification: Report of research in 1997. Final report to Southwest Fisheries Science Center, Olympic Coast National Marine Sanctuaries, University of California at Santa Cruz, and Cornell University. Cascadia Research, 218_ W Fourth Ave., Olympia, WA 98501. 41pp.

Calambokidis, J. L. Schlender, and J. Quan. 1998b. Marine mammal observations and mitigation associated with USGS surveys in the southern California Bight in 1998. Final Report to U.S. Geological Survey, Menlo Park, California. Cascadia Research, 218_W Fourth Ave., Olympia, WA 98501. 14pp. 